\title{
Update on the management of rosacea
}

This article was published in the following Dove Press journal:

Clinical, Cosmetic and Investigational Dermatology

7 April 2015

Number of times this article has been viewed

\author{
Allison P Weinkle \\ Vladyslava Doktor ${ }^{2}$ \\ Jason Emer $^{3}$ \\ 'School of Medicine, University of \\ California San Diego, La Jolla, CA, \\ ${ }^{2}$ Dermatology Department, St John's \\ Episcopal Hospital, Queens, NY, \\ ${ }^{3}$ Spalding Drive Plastic Surgery and \\ Dermatology, Beverly Hills, \\ CA, USA
}

\begin{abstract}
Refining diagnostic criteria has identified key characteristics differentiating rosacea, a chronic skin disorder, from other common cutaneous inflammatory conditions. The current classification system developed by the National Rosacea Society Expert Committee consists of erythematotelangiectatic, papulopustular, phymatous, and ocular subtypes. Each subtype stands as a unique entity among a spectrum, with characteristic symptoms and physical findings, along with an intricate pathophysiology. The main treatment modalities for rosacea include topical, systemic, laser, and light therapies. Topical brimonidine tartrate gel and calcineurin inhibitors are at the forefront of topical therapies, alone or in combination with traditional therapies such as topical metronidazole or azelaic acid and oral tetracyclines or isotretinoin. Vascular laser and intense pulsed light therapies are beneficial for the erythema and telangiectasia, as well as the symptoms (itching, burning, pain, stinging, swelling) of rosacea. Injectable botulinum toxin, topical ivermectin, and microsecond long-pulsed neodymium-yttrium aluminum garnet laser are emerging therapies that may prove to be extremely beneficial in the future. Once a debilitating disorder, rosacea has become a well known and manageable entity in the setting of numerous emerging therapeutic options. Herein, we describe the treatments currently available and give our opinions regarding emerging and combination therapies.
\end{abstract}

Keywords: rosacea, vascular laser, rhinophyma, management, guidelines

\section{Introduction and epidemiology}

Fascination with rosacea has been historically illustrated in medical art and literature, with imagery found in the Louvre dating back to the 15 th century. ${ }^{1}$ Through the refinement of diagnostic criteria, several key characteristics differentiating rosacea from common skin findings have been identified, particularly central facial erythema and acneiform papules and pustules. Specific sparing of the perioral and periocular regions has emerged as an essential criterion for the diagnosis. ${ }^{2}$ In 2002, the National Rosacea Society Expert Committee developed a classification system for rosacea in order to standardize subtypes and variants that has since been widely accepted and continues to aid in research and epidemiological studies. ${ }^{3}$ The committee defined four subtypes based on clinical characteristics: subtype I, or erythematotelangiectatic rosacea (ETR), defined by flushing and persistent central facial erythema (Figure 1); subtype II, or papulopustular rosacea (PPR), consistent with constant erythema and transient pustules and papules in the central facial distribution (Figure 2); subtype III, or phymatous rosacea, characterized by thickened skin with irregular contours overlying the ears, cheeks, chin (gnathophyma), forehead (metophyma), and nose (rhinophyma) (Figure 3); and subtype IV, or ocular rosacea, represented by a watery, burning, dry,
Correspondence: Jason Emer Spalding Drive Plastic Surgery, I20 S Spalding Drive, Suite 315, Beverly Hills, CA, USA 90212

Tel +l 3102752467

Email jason.emermd@gmail.com 


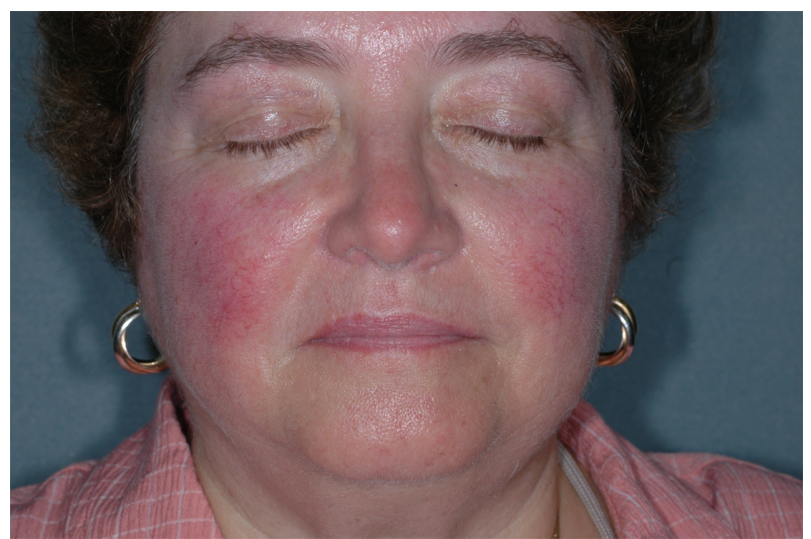

Figure I Erythematotelangiectatic rosacea.

Note: Central facial erythema (most prominently on the cheeks) with telangiectasias.

itchy, and light sensitive ocular sensation with a bloodshot appearance. An associated cutaneous rosacea may or may not be present (Figure 4). However, a wide range of overlapping symptoms makes coinciding subtypes a clinical reality.

The prevalence of rosacea in recent years ranges from $1 \%$ to $22 \%$ depending on the methodology and population sample analyzed. ${ }^{46}$ Reports from general population surveys assess higher sample numbers and may be more reflective of overall prevalence, whereas reports from dermatology clinics represent a more select population and yield smaller prevalence ranges. More recently, large retrospective database studies have yielded prevalence rates ranging from $1.3 \%$ to $2.1 \% .^{7-12}$ Such low rates may be misrepresentative since the administrative databases only recorded patients with severe rosacea symptoms, potentially missing a significant percentage of patients with mild disease.

Generally, women are more often affected than men. Subtype I (ETR) is found to be most prevalent, followed by subtype II (PPR), and rhinophyma is seen mostly in men over

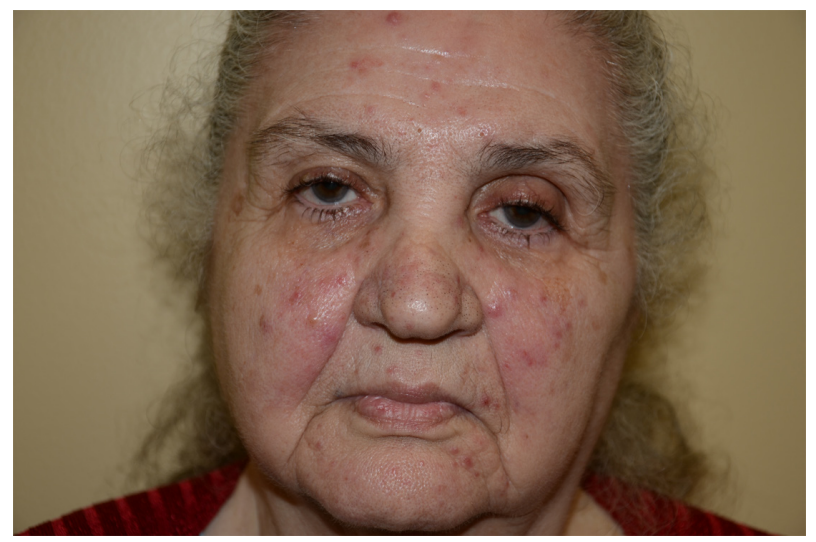

Figure 2 Papulopustular rosacea.

Note: Multiple papules and pustules on the central face, lacking comedones and sparing the perioral area.

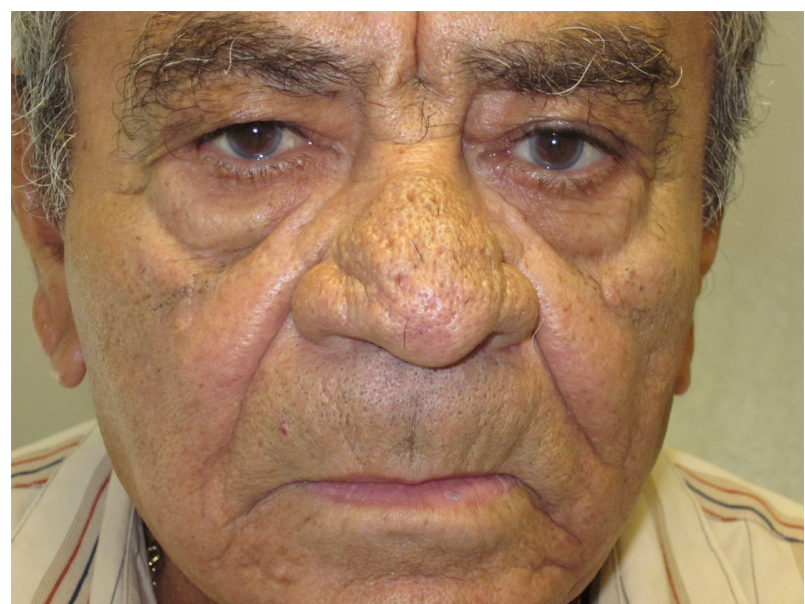

Figure 3 Phymatous rosacea.

Note: Thickened, glandular skin of the nose, creating a cosmetic deformity.

40 years of age. ${ }^{13}$ Ocular rosacea is difficult to diagnose due to wide diagnostic criteria; consequently, incidence rates range from $6 \%$ to $72 \%$, with the greatest prevalence reported from ophthalmology clinics. Unlike facial rosacea, ocular rosacea affects both sexes equally. ${ }^{14}$ The prevalence rates are highly dependent on the classification system, cohort selection, and methodology of collection. Considering these limitations, rosacea as a dermatological entity might be more common than previously suspected.

\section{Natural history and pathophysiological mechanisms underlying rosacea}

Despite the depth of current research, the pathophysiology of rosacea remains primarily theoretical and requires further investigation. There is continued debate between rosacea

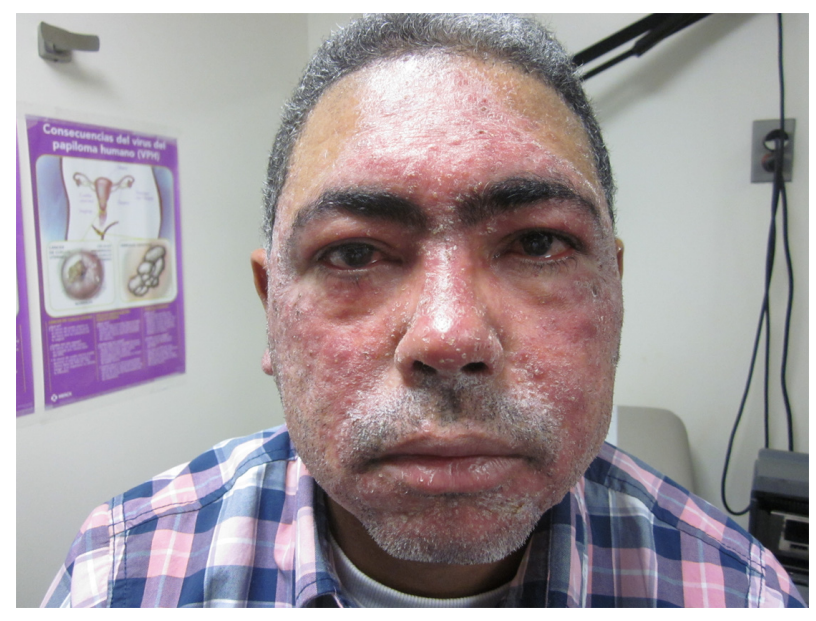

Figure 4 Ocular rosacea.

Note: Erythematous conjunctiva with increased watery discharge in the setting of acutely flared granulomatous rosacea. 
variants representing distinct phenotypes or different stages within one pathological progression. Histologically, dilated lymphatics and blood vessels, as well as perivascular infiltration of $\mathrm{CD}^{+}$helper T-cells, macrophages, and mast cells can be readily seen. ${ }^{15}$ In healthy skin, activation of keratinocyte toll-like receptors (TLRs) by pathogenic cell wall fragments stimulates the cells to coordinate an appropriate defense response, releasing antimicrobial peptides (AMPs) such as cathelicidins and defensins. Originally synthesized as propeptides, these AMPs remain inactive until cleaved by proteases into active fragments. In rosacea, genetic predisposition may precipitate an inappropriate response to different environmental stimuli via TLRs including extremes of temperature, abnormal microbial skin colonization, and ultraviolet light exposure.

The first identified human cathelicidin AMP, LL-37, is released by keratinocytes and cleaved by skin serine proteases (kallikrein 5) into its immunogenic antimicrobial form. Specifically, vitamin D activation by ultraviolet light exposure and endoplasmic reticulum stressors sensed by TLRs on keratinocytes have been shown to induce increased expression of cathelicidin LL-37, triggering molecular cascades ultimately resulting in erythema. ${ }^{16}$ This partially explains why the face, a highly sun-exposed area, is the main site affected in rosacea. ${ }^{17}$ LL-37 has been extensively involved in describing the pathogenic inflammatory response, impaired antimicrobial activity, and vascular dysfunction of rosacea.

Another trigger for cutaneous protease activation of cathelicidins is upregulation of TLR-2 in keratinocytes by Demodex folliculorum, a species of commensal saprophytic mite that colonizes pilosebaceous follicles of the skin. D. folliculorum releases an antigen that sensitizes TLR-2 on keratinocytes to induce the pathway of inflammation associated with protease activation of AMPs, including LL-37. ${ }^{18,19}$ Other microbial agents reportedly associated with rosacea are Bacillus oleronius, Staphylococcus epidermidis, Helicobacter pylori, and Chlamydophila pneumoniae. The exact mechanisms implicating the aforementioned microorganisms in ERT and PPR are yet to be identified or substantiated. ${ }^{20}$

In addition to erythema, neurocutaneous symptoms, including pain, burning, and stinging, have also been reported in rosacea. Activation of peripheral sensory nerve endings like transient receptor potential channels by heat, cold, alcohol, spicy foods, and exercise releases vasoactive neuropeptides that contribute to neurogenic inflammation. ${ }^{21}$ As a result, not only do the blood vessels adapt and become hyperpermeable, allowing for increased blood flow and influx of inflammatory cells, but lymphatic vessels also expand to contribute to characteristic flushing, erythema, and edema. Dilation of precapillary arterioles and post-capillary venules allow protein leakage and leukocyte recruitment via upregulation of selectins and cell adhesion molecules. ${ }^{16}$ Future research will help to clarify the exact pathophysiological mechanisms involved in rosacea. Currently, it is clear that the innate immune and the sensory and autonomic nervous systems are overstimulated with dysregulated interactions, leading to a chronic pathological inflammatory state. Defining the precise molecular interactions and the importance of genetic predisposing factors are puzzle pieces that remain to be solved.

\section{Current and emerging treatments: topical, systemic, laser, and light therapies}

No single treatment is completely curative for rosacea. Fortunately, many treatments have been studied and can give relief when used in the right clinical scenario (Table 1). Pharmacological agents, when used in combination with medical devices, show better results than either treatment alone and can provide improvements never thought possible in the past (Figure 5). Since rosacea is a chronic inflammatory condition that waxes and wanes, with many triggers, the goal of treatment should be to subside acute flares with rapid-acting treatments and maintain the results with lifestyle modification and prolonged combination therapy. The avoidance of triggers, particularly ultraviolet light exposure, is critical for long-term improvement and disease control, and should be an essential component of patient education when prescribing at-home skin care and lifestyle adjustments.

\section{Topical therapies}

Brimonidine tartrate gel (Mirvaso ${ }^{\circledR}$, Galderma Laboratories, Fort Worth, TX, USA), an $\alpha-2$ adrenergic receptor agonist, is the only approved topical treatment for the persistent facial redness of rosacea and works by reversing skin vasodilation. In a recent year-long study, brimonidine tartrate gel $0.5 \%$ applied once daily proved to be both efficacious and safe, regardless of the presence of concomitant therapies. ${ }^{22}$ The clinician's erythema assessment, patient's self-assessment, telangiectasia grading assessment, and inflammatory lesion count were utilized to quantify disease severity. ${ }^{23}$ Three hours following application, the clinician's erythema assessment and patient's self-assessment were reassessed and found to be significantly improved, an effect that was maintained throughout the study. Supporting this result, Jackson et al showed improvement in facial erythema within 30 minutes of initial daily application of brimonidine tartrate in Phase III 
Table I Rosacea subtypes and corresponding topical, oral, and alternative treatments

\begin{tabular}{|c|c|c|c|c|}
\hline Treatment & Ocular & Phymatous & PPR & ETR \\
\hline \multicolumn{5}{|l|}{ Topical $^{30}$} \\
\hline \multirow[t]{4}{*}{ FDA-approved } & - & - & Metronidazole $0.75 \%, 1 \% 27,28,33-35,61$ & Brimotidine tartrate gel $0.5 \%^{22-24}$ \\
\hline & & & Azelaic acid I5\%27,28,60 & Oxymetazoline solution $0.05 \%$ \\
\hline & & & Sodium sulfacetamide $10 \%+$ sulfur $5 \%^{29}$ & \\
\hline & & & Ivermectin $1 \%$ cream $^{36-38}$ & \\
\hline \multirow[t]{5}{*}{ Non FDA-approved } & Azithromycin ${ }^{59}$ & - & BP-clindamycin ${ }^{41}$ & BP-clindamycin ${ }^{41}$ \\
\hline & & & Encapsulated BP gel ${ }^{42}$ & Encapsulated BP gel ${ }^{42}$ \\
\hline & & & Tacrolimus ointment ${ }^{64}$ & Tacrolimus $^{64}$ \\
\hline & & & Pimecrolimus I\% cream $^{31-33}$ & Pimecrolimus I\% cream ${ }^{31-33}$ \\
\hline & & & Permethrin $5 \%$ cream $^{34-36,38}$ & Permethrin 5\% cream $^{34-36,38}$ \\
\hline \multirow[t]{7}{*}{ Oral $^{51}$} & Doxycycline $e^{57,58}$ & - & Isotretinoin ${ }^{66,67-69}$ & Isotretinoin ${ }^{66,67-69}$ \\
\hline & Isotretinoin ${ }^{66}$ & & Ivermectin ${ }^{37}$ & \\
\hline & Ivermectin ${ }^{40}$ & & Doxycycline $e^{48,52,54,55,60,61,67}$ & \\
\hline & Tetracyclines $^{51}$ & & Tetracyclines ${ }^{13,43}$ & \\
\hline & Macrolides $^{51}$ & & Macrolides ${ }^{62,63,64}$ & \\
\hline & & & Metronidazole ${ }^{65}$ & \\
\hline & & & Oral zinc ${ }^{76,77}$ & \\
\hline \multirow[t]{7}{*}{ Alternative } & Lid hygiene & Nd:YAG laser ${ }^{122,123}$ & $\begin{array}{l}\text { Novel lotion (caffeine, zinc gluconate, } \\
\text { bisabolol, Eperua falcata bark extract, } \\
\text { and palmitoyl tripeptide-8) }\end{array}$ & Hyaluronic acid $0.2 \%$ cream $^{47}$ \\
\hline & & Er:YAG laser ${ }^{136-139}$ & Quassia amara $4 \%$ ge $^{45}$ & Argon laser ${ }^{83}$ \\
\hline & & $\mathrm{CO}_{2}$ laser ${ }^{124-134,137,138}$ & Hyaluronic acid $0.2 \%$ cream $^{47}$ & 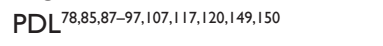 \\
\hline & & $\mathrm{PDL}^{|3|}$ & Onabotulinumtoxin $A^{151,152}$ & IPL $98-111$ \\
\hline & & $\begin{array}{l}\text { Surgical (blade and } \\
\text { radio) excision } \\
\mid 21,136\end{array}$ & $\begin{array}{l}\text { Other natural Ingredients (botnicals and } \\
\text { anti-inflammatories) }\end{array}$ & KTP laser ${ }^{13-117}$ \\
\hline & & Cryosurgery & & Nd:YAG laser ${ }^{125}$ \\
\hline & & Dermabrasion & & Onabotulinumtoxin $A^{151,152}$ \\
\hline
\end{tabular}

Abbreviations: BP, benzoyl peroxide; ETR, erythematotelangiectatic rosacea; PPR, papulopustular rosacea; Nd:YAG, neodymium:yttrium-aluminum-garnet laser; Er:YAG, erbium:yttrium-aluminum-garnet; PDL, pulsed dye laser; IPL, intense pulsed light; KTP, potassium titanyl phosphate; FDA, US Food and Drug Administration.

clinical studies. ${ }^{24}$ Oxymetazoline, a potent $\alpha-1$ and partial $\alpha-2$ receptor agonist, is another efficacious agent for reducing facial erythema, with data primarily limited to case reports, and is now in clinical development for the treatment of ETR. In two adults with refractory erythema and flushing associated with rosacea, oxymetazoline nasal solution $0.05 \%$ applied to facial skin demonstrated significant decreased erythema one hour after application that progressed to dra-
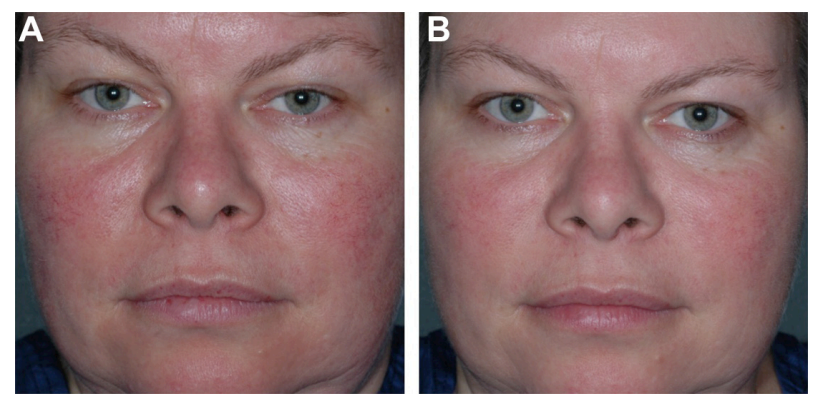

Figure 5 Before $(\mathbf{A})$ and after $(\mathbf{B})$ injectable botulinum toxin (Botox ${ }^{\circledR}, 10 \mathrm{U}, 0.05$ $\mathrm{mL}$ aliquots every $\mathrm{I}-2 \mathrm{~cm}$ ) intradermally into each cheek in combination with pulsed dye laser $(10 \mathrm{~mm}, 10 \mathrm{msec}, 7 \mathrm{~J} / \mathrm{cm})$.

Note: Clinical results and symptomatic relief were seen rapidly after the treatments. matic improvement within 3 hours and remained throughout the day ${ }^{25}$ (Figure 6).

Some of the more commonly used US Food and Drug Administration (FDA)-approved topical agents for PPR are metronidazole and azelaic acid, both of which are available in a variety of strengths and formulations. The efficacy, safety, and cost-effectiveness of both agents are well demonstrated in a number of well controlled randomized studies. ${ }^{26} \mathrm{~A}$ few
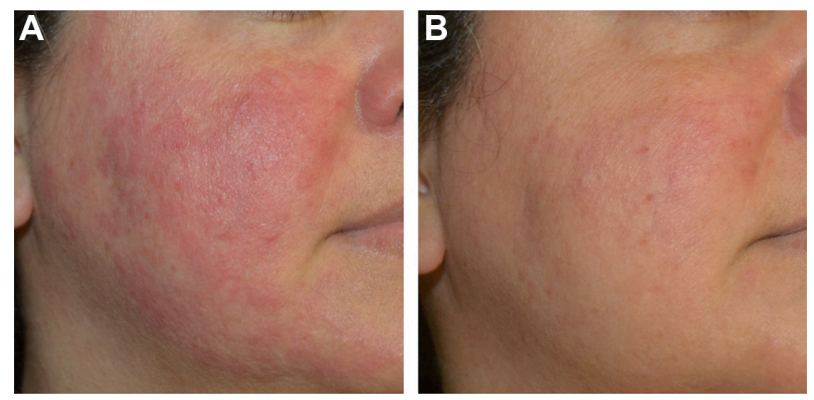

Figure 6 Before $(\mathbf{A})$ and after $(\mathbf{B})$ oxymetazoline $\left(\right.$ Afrin ${ }^{\circledR}$ ) combined with a topical moisturizing cream $\left(\mathrm{CeraVe}^{\circledR}\right)$ applied twice daily. Significant improvement in facial erythema was seen after only one day of application. 
studies show comparable efficacy of metronidazole and azelaic acid, with one study of azelaic acid gel 15\% twice daily yielding a superior reduction in facial erythema versus metronidazole gel $0.75 \%$ twice daily after 8 weeks of use. ${ }^{27,28}$ Long available sodium sulfacetamide $10 \%+$ sulfur $5 \%$ cleansers and leave-on formulations have also proven to be efficacious for the treatment of inflammatory lesions and facial erythema based on small studies; however, they are not used as frequently, perhaps due to their malodorous sulfur content, irritant potential, and limited published data. ${ }^{29}$ The mechanisms of action for these topical agents are unknown and the decision to utilize monotherapy or combination regimens depends on the severity of PPR.

There are a number of alternative topical non-FDAapproved therapies for patients with rosacea that is refractory to primary topical treatments. These agents include topical calcineurin inhibitors such as tacrolimus and pimecrolimus, macrolides such as erythromycin, clindamycin, and azithromycin, and others such as retinoids, permethrin, benzoyl peroxide (BP), and BP-clindamycin. Their therapeutic benefits are widely recognized despite the limited evidence in the small number of clinical studies. ${ }^{30}$ Pimecrolimus cream $1 \%$ has been used to treat both PPR and ETR with mixed results, but worthy of a trial in unmanageable cases..$^{31,32}$ In an open-label randomized study of 49 patients, pimecrolimus $1 \%$ cream was as effective as metronidazole $1 \%$ cream. ${ }^{33}$ The senior author (JE) has found considerable benefit in using topical pimecrolimus in combination with oral treatments and/or vascular laser therapy for both ETR and PPR types, and this is his "go-to" therapy for patients with refractory or flared moderate to severe presentations.

Macrolides, such as erythromycin and its analogs, clindamycin and azithromycin, have limited data with regard to reduction of inflammatory lesions and are not recommended as treatments of choice due to potential induction of antibiotic-resistant bacterial strains..$^{30}$ However, many practicing physicians continue to use these treatments as first-line because they believe them to have intrinsic anti-inflammatory properties that not only improve facial erythema and papules but also the associated symptoms of rosacea.

The antiparasitic properties of permethrin showed efficacy in one study of 63 subjects comparing permethrin cream, topical metronidazole, and placebo. ${ }^{34}$ Patients were randomly divided into three treatment groups and received either permethrin $5 \%$ cream $(n=23)$, metronidazole $(n=20)$, or placebo cream $(n=20)$ for up to 2 months of treatment twice daily. Outcomes of erythema, numbers of papules/pustules/nodules, and $D$. folliculorum colonization were assessed at baseline and every 15 days. D. folliculorum colonization was reduced by both agents; however, permethrin $5 \%$ had a greater effect than metronidazole. Both active treatments reduced erythema and papules, but had no effect on pustules or telangiectasia. Overall, permethrin 5\% was found to be a new and powerful tool against dense colonization of $D$. folliculorum, a proposed key player in the pathogenesis of rosacea.

These results clarify previous equivocal findings of permethrin 5\% cream and metronidazole $0.75 \%$ gel in a pilot study of six patients who used each therapy on half of the face for up to 10 weeks twice daily. ${ }^{35}$ More recently, a case study of an immunocompetent patient with refractory rosacea secondary to Demodex dermatitis demonstrated symptom resolution with oral ivermectin and permethrin 5\% cream. ${ }^{36}$

A novel topical agent, ivermectin $1 \%$ cream, recently approved by the FDA, was studied in the treatment of PPR in two randomized, double-blind, vehicle-controlled Phase III studies of identical design conducted in the USA $(n=683)$ and Canada $(n=688) \cdot{ }^{37}$ Stein et al compared once-daily ivermectin $1 \%$ cream with vehicle for a duration of 12 weeks utilizing the investigator global assessment of disease and inflammatory lesion counts as efficacy parameters. A statistically significant percentage of patients at both trial sites treated with ivermectin $1 \%$ compared with vehicle achieved success according to the investigator global assessment, defined as “clear" or "almost clear" skin at week 12. There was also a significantly greater percent reduction in inflammatory lesion counts in the treatment group when compared with control. Adverse events were assessed throughout and were found to be more frequent in the patients treated with vehicle only. The most common complaints were skin burning, pruritus, and dry skin, with no serious adverse events reported. The results of these two 12-week studies identified ivermectin 1\% cream as unequivocally potent and safe in treating inflammatory lesions in PPR patients.

Developed from the naturally occurring antiparasitic compound avermectin, ivermectin has both anti-inflammatory and antiparasitic properties that have been utilized orally in the treatment of rosacea-like demodicidosis with topical promethazine and as monotherapy topically for head lice and orally for chronic blepharitis secondary to Demodex. ${ }^{38-40}$ Selective binding of ivermectin to glutamate-gated chloride channels in invertebrates has been shown to reduce Demodex colonization in both demodicidosis and blepharitis. Ivermectin induces anti-inflammatory effects via nuclear factor- $\kappa \mathrm{B}$ pathway inhibition and subsequently decreases the release of inflammatory cytokines. Given that none of the classic rosacea therapies address both the inflammatory and infectious pathogenesis 
of the disorder, innovative use of ivermectin may prove to be beneficial in the future and warrants further investigation.

Benzoyl peroxide and antibiotic combinations, eg, BPerythromycin and BP-clindamycin, have long been used for reduction of papulopustular lesions. In a randomized, double-blind, vehicle-controlled trial of BP-clindamycin gel, daily application demonstrated efficacy in 26 patients with moderate to severe rosacea. ${ }^{41}$ The percentage change in number of papules and pustules from beginning to end of the 12 weeks was reduced by a mean $71.3 \%$ in the treatment group compared with $19.3 \%$ in the vehicle only group, with a statistically significant difference between the two results. Side effects of itching, burning, and bleaching of hair and clothing were reported in eleven patients. Consequentially, a recent randomized, dose-ranging Phase II study of $1 \%$ and $5 \%$ BP-encapsulated in silica microcapsules proved to be both highly effective and well tolerated in PPR patients, as the encapsulation added protection for the epidermis from the irritant effects of $\mathrm{BP}^{42}$

Natural cosmeceutical options serve as an additional branch of the market available to rosacea patients. Natural ingredients reported in the literature that provide hydrating, anti-inflammatory, and antioxidant properties capable of calming the inflammatory manifestations of rosacea include colloidal oatmeal, niacinamide, feverfew, licorice, teas, coffeeberry, aloe vera, chamomile, turmeric, and mushroom extracts. ${ }^{43}$ Further, a novel topical lotion (Redness Neutralizer $^{\circledR}$, SkinCeuticals, New York, NY, USA) containing caffeine, zinc gluconate, bisabolol, Eperua falcata bark extract, and palmitoyl tripeptide-8, was used twice daily in a group of 25 patients with PPR who had been previously treated successfully with topical or oral therapy, but were unsatisfied with the remaining background erythema. ${ }^{44}$ All efficacy categories demonstrated statistically significant improvement between baseline and follow-up at weeks 4 and 8. Although one patient developed burning and increased erythema and withdrew from the study, the remaining 24 patients found the treatment very tolerable without clinical signs of irritation. Overall, $95 \%$ of patients were satisfied with the products and the results after 8 weeks of twice-daily use.

In another single-center, open-label study, a group of 30 patients with rosacea of variable severity were treated with 4\% Quassia amara extract topical gel for 6 weeks. Reportedly, Q. amara possesses antiparasitic and antiinflammatory properties that have the capability to decrease the inflammatory response with few complications. ${ }^{45}$ Efficacy comparable with that of first-line topical treatments like azelaic acid and metronidazole was observed after Q. amara treatment, with superb tolerability. Finally, a formulation of low molecular weight hyaluronic acid sodium salt $0.2 \%$ cream (Bionect ${ }^{\circledR}$ Cream, Innocutis Holdings, Charleston, SC, USA) applied twice daily for 8 weeks showed a statistically significant reduction in papules, erythema, burning, stinging, and dryness in a small study. ${ }^{46}$ Along with excellent tolerability, a reduction in papules, erythema, burning/ stinging, and dryness was clearly apparent by week 4 and remained by the final visit at week 8 . Notably, erythema was reduced by the greatest amount, with an approximate $50 \%$ improvement by week 2 . This study demonstrates the importance of skin barrier maintenance and repair in the pathogenesis of rosacea. With a hydrophilic structure, low molecular weight hyaluronic acid penetrates the stratum corneum where it interacts with fibrin and collagen to support remodeling of the extracellular matrix. This mechanism, along with induction of the antimicrobial peptide $\beta$-defensin 2 release from keratinocytes, ultimately accelerates re-epithelialization and reduces pain and edema. ${ }^{47}$

\section{Systemic therapies}

Modified-release doxycycline $40 \mathrm{mg}$ once daily (Oracea ${ }^{\circledR}$, Galderma Laboratories) is the only systemic agent that is approved by the FDA for the treatment of PPR and provides anti-inflammatory effects with subantimicrobial dosing. The formulation allows for immediate release of $30 \mathrm{mg}$ with delayed release of $10 \mathrm{mg}$ once ingested. ${ }^{48}$ Through inhibition of numerous matrix metalloproteinases, a reduction in the quantity and activity of serine protease kallikrein 5 results in decreased production of cathelicidin LL-37, the same AMP that has been highlighted in the pathogenesis of rosacea. ${ }^{49}$ Key anti-inflammatory actions of doxycycline in rosacea include: downregulation of cytokines, reducing neutrophil infiltration, inhibition of nitric oxide and its vasodilatory effects, reduction of reactive oxygen species, slowing connective tissue destruction, and inhibition of matrix metalloproteinases. ${ }^{50}$

Several studies have shown the effectiveness of doxycycline at subantimicrobial doses in the treatment of PPR, both as monotherapy and in conjunction with topical agents. ${ }^{51}$ In a pivotal randomized, dose-ranging, double-blind trial, similar therapeutic effects were seen in patients with PPR using metronidazole $1 \%$ gel and either $40 \mathrm{mg}$ or $100 \mathrm{mg}$ delayed-release doxycycline over 16 weeks. ${ }^{52}$ Notably, no statistically significant difference was seen between the two treatment groups in any outcome measures; however, adverse events, including nausea, vomiting, diarrhea, and abdominal pain, occurred solely in those treated with doxycycline 
at an antibiotic dose. Subsequently, a large-scale study demonstrated excellent results in 826 patients with mild to moderately severe rosacea taking daily doxycycline $40 \mathrm{mg}$ monotherapy (30 mg immediate-release and $10 \mathrm{mg}$ delayedrelease beads). ${ }^{53,54}$ Nearly $75 \%$ of participants achieved clear or near clear results on the five-point investigator global assessment scale.

Combination therapy has demonstrated more substantial improvements than monotherapy. Oral doxycycline as well as minocycline with azelaic acid or metronidazole has shown substantial improvements in inflammatory lesion counts in multiple studies. ${ }^{55-65}$

Alternative systemic therapies for PPR and ocular rosacea, which are not FDA-approved, include tetracycline derivatives (doxycycline and minocycline at antimicrobial doses), macrolides (erythromycin, azithromycin, and clarithromycin), metronidazole, and oral isotretinoin. There are several considerations when using systemic treatments, including allergic reactions, drug rash with eosinophilia and systemic symptoms (DRESS syndrome), cutaneous hyperpigmentation, benign intracranial hypertension, autoimmune hepatitis, and drug-induced lupus-like syndrome. More common concerns, and ones to discuss with patients at treatment onset, include gastrointestinal intolerance (antibiotics), metallic taste (macrolides $>$ metronidazole), drug interactions, and photosensitivity (doxycycline $>$ minocycline). Tetracyclines should be avoided in pregnant or lactating women and in children with developing teeth because they can result in permanent staining (dark yellow-gray teeth with a darker horizontal band across the top and bottom rows of teeth), and may also affect bone and tooth growth.

When patients cannot tolerate tetracyclines due to photosensitivity or gastrointestinal adverse effects, such as pill esophagitis, azithromycin has been suggested as an alternative oral treatment option. ${ }^{62}$ In one case report, a 52-yearold patient with rosacea was successfully treated with azithromycin $500 \mathrm{mg}$ daily after failing numerous regimens, including topical BP, topical metronidazole twice daily, oral metronidazole $500 \mathrm{mg}$ for 2 weeks, oral isotretinoin $10 \mathrm{mg}$ for one month, and oral doxycycline $200 \mathrm{mg}$ for one month. ${ }^{63}$ With dramatic improvement noticed after 2 weeks of treatment, the patient's lesions had almost completely disappeared by week 10, with no medication-induced side effects. Another case study in a post-menopausal woman of the same age ( 52 years) with progressive rosacea symptoms and ocular involvement showed gradual erythema and papulopustule improvement while using combination therapy with tacrolimus $0.1 \%$ ointment for 30 days in addition to azithromycin $1,000 \mathrm{mg}$ daily for 45 days, then $500 \mathrm{mg}$ daily for an additional 45 days. ${ }^{64}$ Historical data show than oral metronidazole $200 \mathrm{mg}$ taken twice daily for 6 weeks resulted in marked improvement in papular and pustular lesions; however, its link to potential side effects such as neuropathy, seizures, and a disulfiram-like reaction have limited further research. ${ }^{65}$

Oral isotretinoin is typically reserved for severe cases of all rosacea subtypes. This retinoid derivative of vitamin A not only reduces the size of sebaceous glands and subsequently sebum production, but also possesses anti-inflammatory, immunomodulatory, and antineoplastic properties. ${ }^{66}$ For acne, it is commonly given for a duration of 6 months in daily doses ranging from $0.2 \mathrm{mg} / \mathrm{kg}$ to $1.0 \mathrm{mg} / \mathrm{kg} .{ }^{13}$ Participation in the iPledge program, which is mandated by the FDA in order to minimize the risk of teratogenicity from pregnancy while on therapy, as well as numerous drug-induced side effects, such as mucosal dryness, retinoid dermatitis, photosensitivity, and increased blood triglycerides and liver function tests, make prescribing more tedious.

In a large dose-finding, randomized, double-blind trial comparing the use of different systemic isotretinoin dosages with both doxycycline and placebo, the ultimate effective dose of isotretinoin was found to be $0.3 \mathrm{mg} / \mathrm{kg}$ for a minimum duration of 3 months. ${ }^{67}$ Patients with subtypes II (papulopustular) and/or III (phymatous) rosacea were randomly assigned into one of five treatment groups: doxycycline $100 \mathrm{mg}$ daily for 14 days then $50 \mathrm{mg}$ daily $(\mathrm{n}=143)$, isotretinoin $0.1 \mathrm{mg} / \mathrm{kg}$ $(\mathrm{n}=109), 0.3 \mathrm{mg} / \mathrm{kg}(\mathrm{n}=142)$, or $0.5 \mathrm{mg} / \mathrm{kg}(\mathrm{n}=109)$, or placebo $(n=46)$. These groups were followed until the interim analysis, at which point isotretinoin $0.3 \mathrm{mg} / \mathrm{kg}$ stood out as the most efficacious and tolerable dosage. The two other isotretinoin dosage arms were closed, leaving doxycycline and isotretinoin $0.3 \mathrm{mg} / \mathrm{kg}$ for the final analysis after 12 weeks of treatment. Overall, isotretinoin $0.3 \mathrm{mg} / \mathrm{kg}$ showed statistically significant noninferiority when compared with doxycycline therapy, with investigators documenting complete remission in $24 \%$ of patients treated with isotretinoin $0.3 \mathrm{mg} / \mathrm{kg}$ compared with $13.6 \%$ of patients treated with doxycycline. Notably, more patients in the isotretinoin group reported adverse drug reactions (33\%) compared with the doxycycline group (25\%); however, these differences did not reach statistical significance. For recalcitrant rosacea with problematic relapses, continuous "microdose" isotretinoin $(0.04-0.11 \mathrm{mg} / \mathrm{kg}$ daily) in patients without a risk of teratogenesis has shown promise. ${ }^{68,69}$

For the senior author (JE), oral isotretinoin has been particularly useful in the PPR and phymatous subtypes (Figure 7). When multiple subtypes coexist in patients with rosacea, it is 

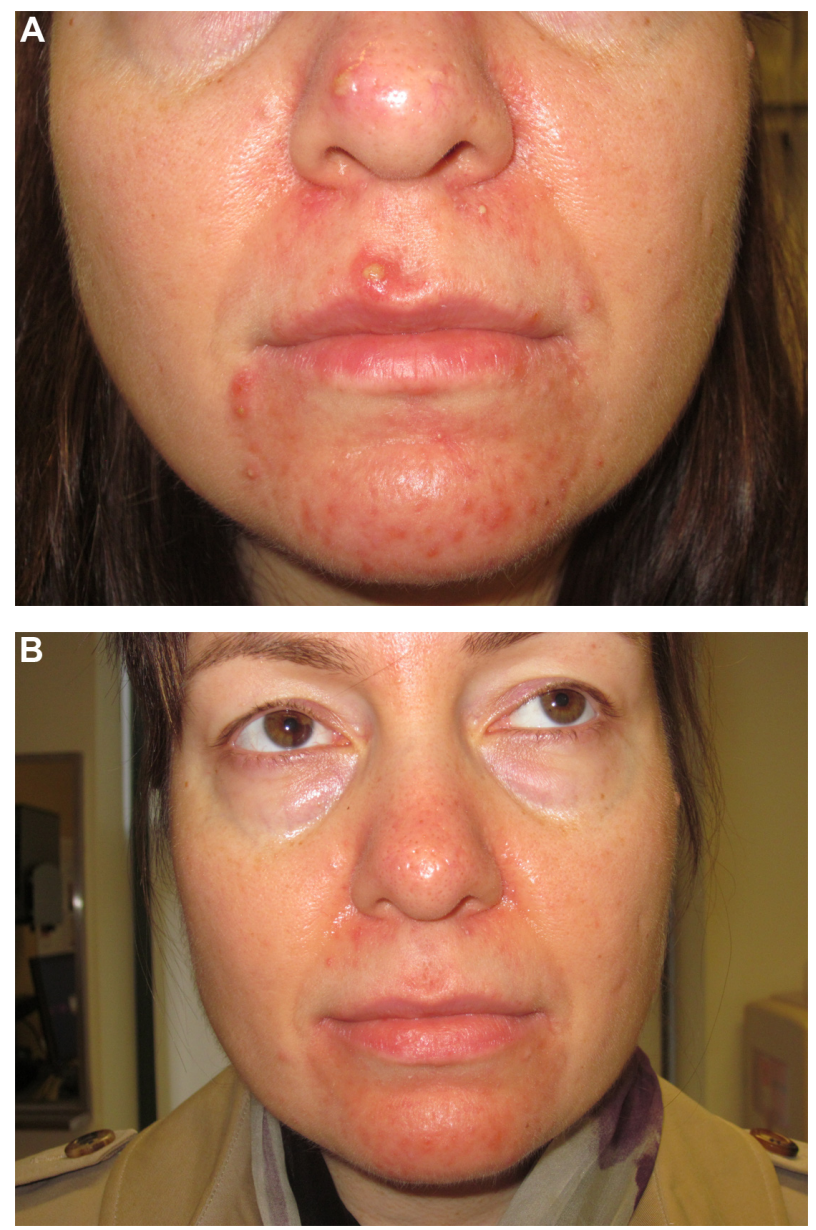

Figure 7 (A) Severe perioral dermatitis (a version of acne-rosacea). (B) Dramatic improvement after initiation of oral isotretinoin.

Note: Full clearance with no recurrence was seen after 20 weeks of therapy.

often beneficial to combine vascular laser treatments and oral isotretinoin. Contrary to historical belief, there is no increased risk of scarring or abnormal wound healing with this combination, and both symptoms of rosacea and central facial erythema and telangiectasia can be reduced dramatically. Many reports of skin sensitivity or fragility while on isotretinoin have been reported, which is a real concern. ${ }^{70,71}$ Therefore, patient education is important before initiating therapy with regards to facial or body waxing, scratching or picking, and exposure to extremes of temperature (hot tubs, steam rooms, skiing) as these can predispose to easier skin trauma. Atypical keloid formation has also been documented following dermabrasion while on isotretinoin. ${ }^{72,73}$ However, recent controlled investigations have analyzed skin healing in patients on oral isotretinoin therapy and have debunked previous concerns.

One comparative retrospective study assessed the effect of invasive acne scar treatment and laser hair removal in a group of 55 patients on a combination of topical therapy and isotretinoin $0.5 \mathrm{mg} / \mathrm{kg}$ daily compared with a group of
55 patients on topical monotherapy. ${ }^{74}$ Notably, there were no differences between the two groups with regard to adverse outcomes, with no development of keloids, atypical scarring, or delayed wound healing following laser therapy. No complications were seen in 35 patients taking isotretinoin $10 \mathrm{mg} / \mathrm{kg}$ daily for at least one month prior to a mean of 3.1 sessions with $1,550 \mathrm{~nm}$ erbium-doped fiber laser therapy. ${ }^{75}$

Finally, oral zinc sulfate has been proposed as an additional oral treatment for rosacea. In a randomized, controlled, double-blind, crossover study of 19 patients receiving $100 \mathrm{mg}$ zinc sulfate capsules or placebo three times daily, significantly reduced scores were seen in both treatment arms during the zinc treatment arm, with a relative plateau during the placebo phase. ${ }^{76}$ In contrast, a similar trial of $220 \mathrm{mg}$ zinc sulfate dosed twice daily showed no difference in patients receiving zinc therapy versus placebo. ${ }^{77}$ Neither of the studies on oral zinc products produced any side effects of concern. Since both studies did not account for rosacea subtypes, future studies should focus on precise data collection to determine which subtypes, if any, are benefited most by the antioxidant and anti-inflammatory properties of zinc.

\section{Lasers and lights}

Many lasers have created a paradigm shift in the treatment of erythema and telangiectasias associated with rosacea. Those most commonly used include the pulsed dye laser (PDL, 585-595 nm), intense pulsed light (IPL, 500-1,200 nm), potassium titanyl phosphate (KTP, $532 \mathrm{~nm}$ ) laser, and long-pulsed neodymium:yttrium-aluminum-garnet laser (Nd:YAG, 1,064 $\mathrm{nm}) .{ }^{78-82}$ Carbon dioxide $\left(\mathrm{CO}_{2}\right)$ and erbium:yttrium-aluminumgarnet (Er:YAG) induce drastically higher target temperatures resulting in vaporization, and are therefore implemented in ablative correction of rhinophyma and other manifestations of phymatous rosacea. The older generation of argon, copper bromide, and krypton lasers paved the way for new lasers and lights developed specifically for cutaneous vascular lesions with more precision to minimize such side effects as hypopigmentation, atrophic scars, and recovery time.$^{83,84}$ Laser settings used in major studies of the treatment of rosacea with prominent telangiectasia and erythema (Table 2) and phymatous rosacea (Table 3) are outlined in detail, with laser manufacturers listed when specified by the authors. An in-depth review of all the published studies using lasers and/or lights for the treatment of rosacea is beyond the scope of this current review.

\section{Pulsed dye laser}

PDL historically emitted light at $577 \mathrm{~nm}$ and more recently at $585 \mathrm{~nm}$ or $595 \mathrm{~nm}$, all wavelengths that closely correspond 


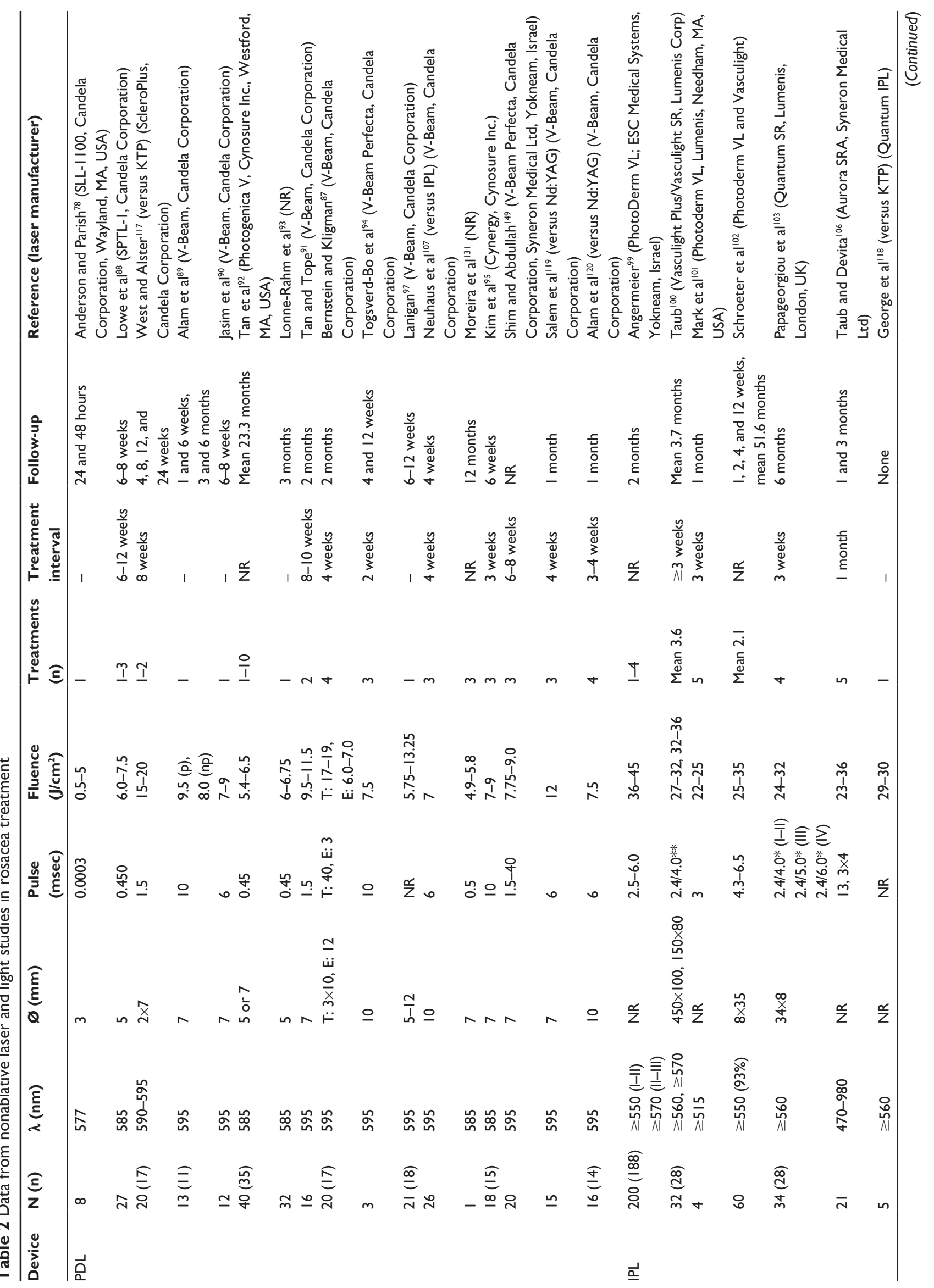




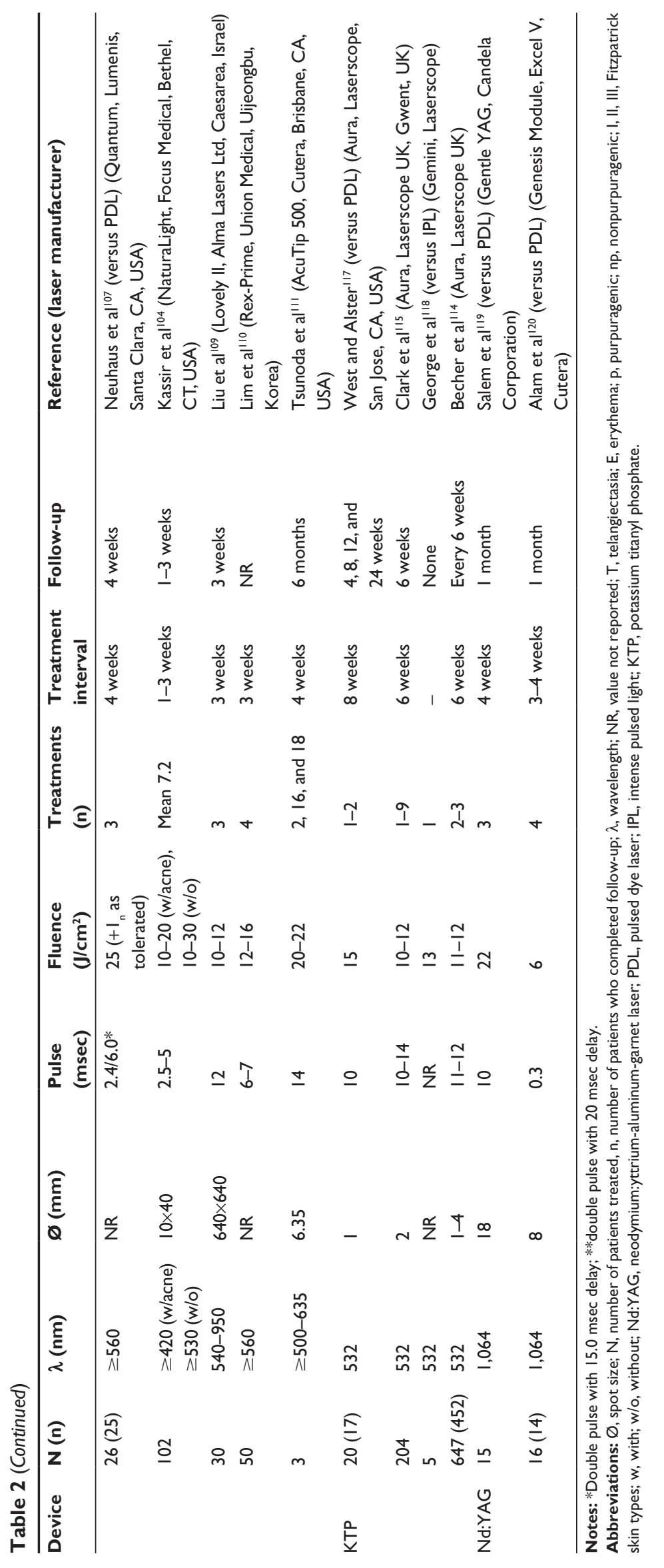




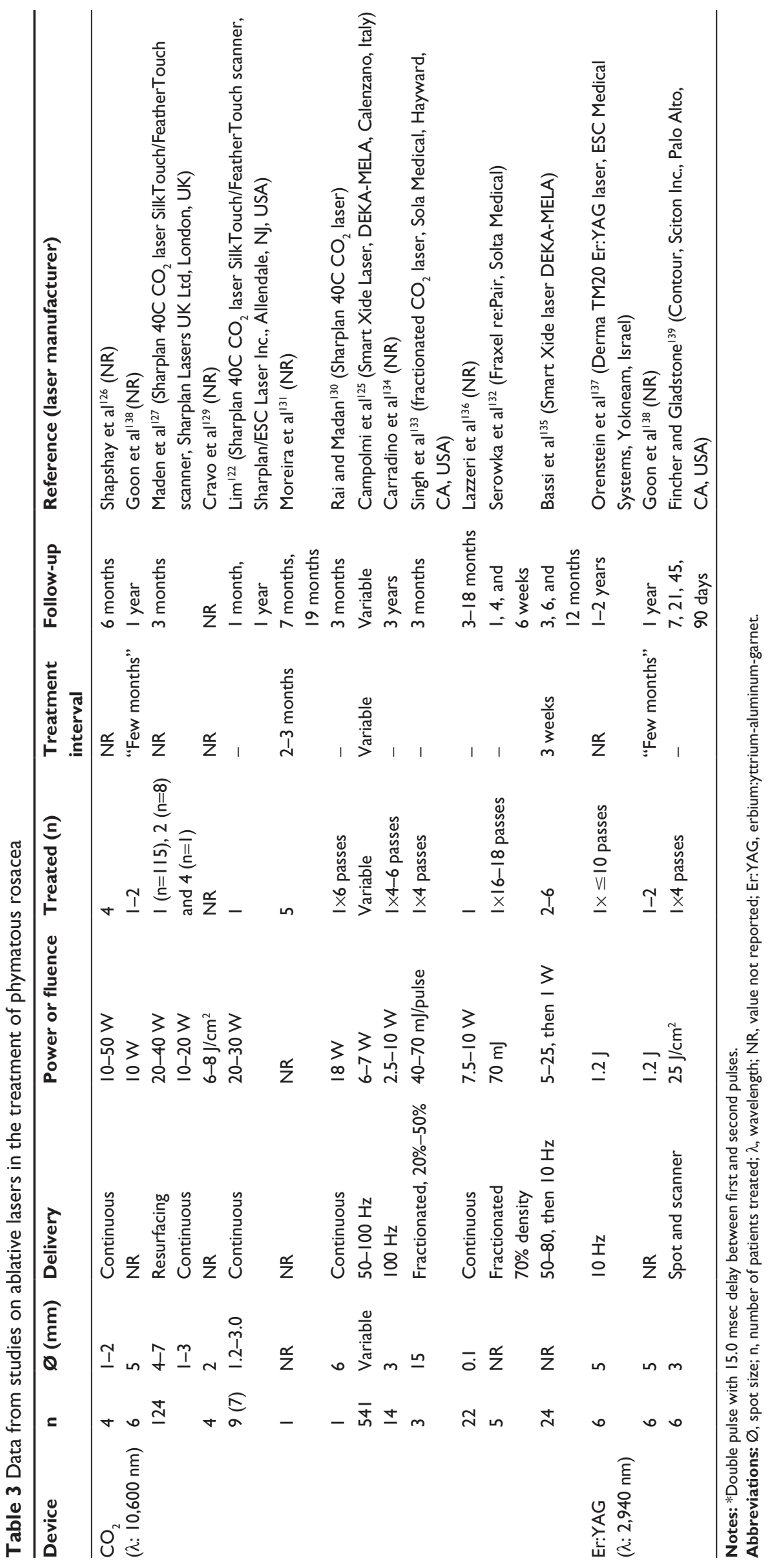


with the absorption peak of oxyhemoglobin and thus target superficial vasculature. ${ }^{78,85}$ Post-treatment purpura was a disadvantage of classic PDL treatments, but has been minimized in modern studies. ${ }^{86}$ The latest generation of PDL utilizes longer pulse durations and has the ability to emit variable energies that specifically target telangiectasias with less purpura and dyspigmentation than previously ("subpurpuric dosing"). ${ }^{87-89}$

PDL has been shown to improve both the clinical findings of rosacea (erythema, telangiectasia) as well as the associated symptoms. ${ }^{87-97,107,117}$ In one study, after verifying sensitivity with a provocative lactic acid test, 32 patients with rosacea were treated with one session of $585 \mathrm{~nm}$ PDL. ${ }^{93}$ Thirty-one patients who were stinger positive before treatment showed decreased scores after treatment, and one patient had the same stinger test score before and after treatment. In addition, biopsies taken before and 3 months after treatment were analyzed immunohistochemically for changes in substance $\mathrm{P}$, calcitonin gene-related peptide, and vasoactive intestinal polypeptide, all of which are neuropeptides implicated in microvascular pathophysiology. Dermal papillae demonstrated a statistically significant reduction in the number of substance P-positive nerve fibers; however, no effect was seen on either vasoactive intestinal polypeptide or calcitonin gene-related peptide immunoreactivity. This finding highlights substance $\mathrm{P}$ as a potential key player in the pathophysiology of the vascular changes prominent in rosacea and responsive to PDL therapy.

\section{Intense pulsed light}

IPL has been shown to be applicable in various clinical settings, including rosacea, port wine stains, disseminated porokeratosis, seborrheic keratosis, sarcoidosis, and hypertrophic keloid scars. ${ }^{98}$ Parameter flexibility enables the targeting of deep vessels, as well as large areas of telangiectasia, erythema, and flushing, but does require clinical expertise and experience to perfect treatments and decrease complications. Most IPL systems provide a large spot size, reducing patient discomfort, increasing efficiency of treatment, and enabling deeper light penetration. When used appropriately, IPL appears to provide impressive results in various settings with a relatively negligible side effect profile. ${ }^{97-111}$

Early on, Angermeier demonstrated 75\%-100\% clearance after one or two treatments in 174 of 188 patients with vascular lesions at a 2-month follow-up. ${ }^{99}$ Soon after, these same results were confirmed in a study specific to rosacea only. ${ }^{100}$ Thirty-two patients treated with doublepulsed IPL for an average of 3.6 times with at least 3-week intervals achieved improved redness (83\%), flushing and texture (75\%) and acneiform breakouts (64\%) subjectively at 3-4-month follow-up self-assessments. Notably, very few patients experienced purpura $(n=1)$, peeling $(n=1)$, or post-inflammatory hyperpigmentation $(n=1)$.

IPL demonstrated a decrease in blood flow (30\%), a decrease in surface area of telangiectasias (29\%), and a decrease in the intensity of erythema (21\%) in one study using a $510 \mathrm{~nm}$ filter. ${ }^{101}$ This implies that IPL treatments have a clinically relevant effect on the local cutaneous vasculature, which is central to the symptomatology seen in patients with rosacea.

Taub et al tackled the persistent background erythema often remaining after effective targeted therapy of telangiectasia in patients with ETR. ${ }^{106}$ Twenty-one patients with ETR received five monthly facial treatments of a electro-optical synergy device combining pulsed light (470-980 nm) with bipolar radiofrequency (Elos, Syneron). The electro-optical synergy parameters were complex, with a combination of short pulses (13 msec light and $80 \mathrm{msec}$ radiofrequency) performed horizontally and long pulses (12 msec light and $85 \mathrm{msec}$ radiofrequency) performed vertically. Outcome measures of erythema and telangiectasia were assessed by clinicians comparing before and after photographs in addition to self-assessment scores. Significant improvement was achieved in both erythema and telangiectasia assessed by both physicians and patients at all follow-up intervals. Notably, patients reported significant improvement in flushing, one of the most psychosocially challenging disease manifestations.

Of note, IPL (560 nm filter) has been compared with nonpurpuric (6 msec) PDL in a head-to-head, randomized, controlled, split-face trial, and it was found that both treatment modalities demonstrated similar efficacy in improving erythema and telangiectasia in 29 patients with ETR. ${ }^{107}$

\section{Potassium-titanyl phosphate laser}

Ideal for linear, arborizing, and discrete telangiectasia, KTP laser, a product of the 1,064 nm yttrium-aluminum-garnet laser family, results from passing Nd:YAG light through a KTP crystal that halves the wavelength, producing a $532 \mathrm{~nm}$ green light. Emitting light twice the frequency of Nd:YAG, KTP interacts with superficial chromophores, making it quite useful for superficial vessels and with less healing time. ${ }^{112-117}$ Although beneficial for such lesions, such low wavelengths have the disadvantage of interacting with melanin and are limited to lighter skin tones due to the risk of post-inflammatory hyperpigmentation. With minimal discomfort, KTP can target vessels $1-3 \mathrm{~mm}$ below the skin surface, and increasing pulse widths enable treatment of vessels of larger diameter. Some recommend cooling the skin with chilled water-based gel and utilizing post-treatment ice, 
basing each treatment session off an endpoint when vascular lesions appear grayish and are no longer readily visible. ${ }^{113}$

PDL (595 nm, $1.5 \mathrm{msec}$ ) and KTP was studied head-tohead in 20 female patients with facial or leg telangiectasias. ${ }^{117}$ Photographs taken before treatment and on four different follow-up visits were scored on a five-point scale (zero to four) by the patient and a blinded physician and nurse in addition to patient-rated 10-point pain scores. Twelve weeks after one to two treatments, PDL resulted in an average telangiectasia improvement score of 3.1 in the lower extremities and 3.8 on the face compared with 1.8 and 2.3 for lesions treated with KTP on the five-point efficacy scale. Despite the clearly superior efficacy of PDL in this study, patients noted significantly more pain, hyperpigmentation, and purpura lasting up to 2 weeks, and therefore may prefer multiple KTP treatments. KTP has also be studied against IPL, with clinical improvements demonstrated for both, but with a significant skin temperature rise immediately after KTP as compared with no change in skin temperature after IPL. ${ }^{118}$

\section{Neodymium:yttrium-aluminum-garnet laser}

Long-pulsed Nd:YAG is efficacious in the treatment of large deep vessels with blue tones. ${ }^{112}$ When evaluated in a split-face comparative study of 15 patients with ETR, both long pulsed Nd:YAG (1,064 nm) and short wavelength PDL yielded comparative responses with regard to erythema and telangiectasia. ${ }^{119}$ This laser is not as commonly used in rosacea because larger blue veins or deep vascular networks are rarely present, but are useful for dilated leg or facial veins or recalcitrant vascular malformations/port wine stains.

$\mathrm{CO}_{2}$ laser and erbium:yttrium-aluminum-garnet laser Many consider ablative lasers such as $\mathrm{CO}_{2}(10,600 \mathrm{~nm})$ and Er:YAG $(2,940 \mathrm{~nm})$ as first-line treatment options for rhinophyma; however, various other surgical techniques have been shown to improve disfigurement, including cold steel, hot loop/radiowave and scalpel excision, electrosurgery, dermabrasion, and cryosurgery. ${ }^{120-139}$ All may be cosmetically limited due to excessive intraoperative bleeding obstructing visualization and causing imprecise tissue removal, along with the risk of scarring. Technological enhancements such as scanned and "superpulsed" systems emit shorter pulses with high power, reducing common adverse effects such as scarring and dyspigmentation. Ablative laser therapy can be used to contour the deformed nasal shape by partial excision of the sebaceous follicle to the bases. Despite transient swelling, erythema, and crusting which require longer healing times than nonablative lasers and risk permanent dyspigmentation, textural changes, and scarring, the ultimate results can be cosmetically and psychosocially life-changing in just one or two treatments (Figure 8).

\section{Clinical challenges: combination therapy and managing erythema in rosacea}

Since rosacea is a chronic inflammatory condition, it is uncommon for a single treatment to effect a permanent cure, and many frequently fall short of dramatic improvement. In mild
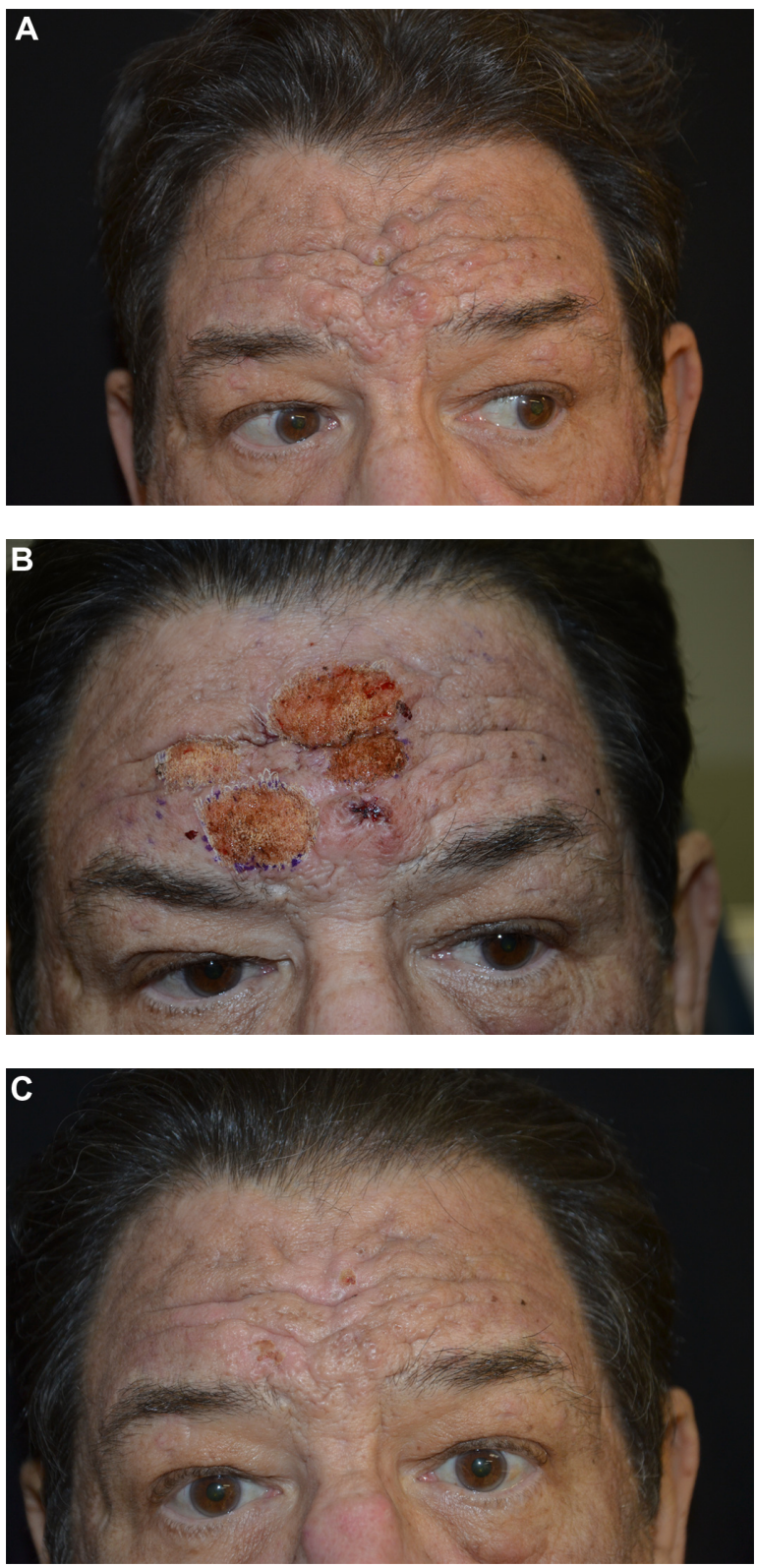

Figure 8 Before (A) and immediately after (B) continuous wave fully ablative carbon dioxide laser treatment, and 2 weeks following $(\mathbf{C})$ treatment for metaphyma (enlargement of sebaceous glands on the forehead).

Notes: Dramatic improvement without any sequelae is seen in the areas of concern for this patient. Similar results are seen with rhinophyma using comparable methods. 
disease, topical treatments and lifestyle modification may be adequate. Most patients, however, have only slight responses to monotherapy and combination approaches are generally required. Erythema and telangiectasias are best treated by laser and light therapies, and often require combination with oral tetracyclines and topical immunotherapy and/or brimonidine topical gel (Mirvaso ${ }^{\circledR}$ ). PPR often responds to a combination of oral tetracyclines with topical metronidazole, but if recurrent, recalcitrant, or severe, may require oral prednisone or isotretinoin. As previously stated, rhinophyma requires surgical or laser interventions for best results. Although oral isotretinoin has been reported to help sebaceous hyperplasia permanently, in the opinion of the senior author (JE) this is not seen in rhinophyma. A recent case report utilizing low-dose isotretinoin (20 mg daily for one year, followed by $10 \mathrm{mg}$ daily for an additional year) prevented troublesome recurrence following $\mathrm{CO}_{2}$ ablation for a 20-year history of sebaceous hyperplasia in a 55-year-old Korean man. ${ }^{140}$

Sebaceous hyperplasia has also troubled transplant patients on immunosuppression. Two cases of cyclosporine-induced sebaceous hyperplasia resolved 3 months after treatment with 10 or $20 \mathrm{mg}$ isotretinoin daily. ${ }^{141}$ No side effects, drug interactions, or transplant-associated complications were experienced. Higher doses of isotretinoin (40 mg each morning and $20 \mathrm{mg}$ each evening) were used to treat refractory sebaceous hyperplasia in a 57-year-old Caucasian female, with reduction in lesion size after one month which was nearly complete by 2 months. ${ }^{142}$ Despite these case reports, in our experience, rhinophyma requires surgical or laser intervention for a cure.

Most importantly, physicians must assess patient concerns and expectations at the first visit and educate about the condition, the long-term treatments required, and the at-home compliance and skin care (gentle cleansing, moisturizing, and photoprotection) needed for best results. ${ }^{143}$

Pathophysiological changes in the erythematous and sebaceous skin of rosacea might differ between patients, yielding nonuniform treatment responses. For example, the vasculature involved in erythematous manifestations could be enlarged, thickened, dilated, or even newly formed, and conventional therapies may only target one dimension of these pathological changes. Thus, multiple modalities are often required and may not yield a permanent cure, but require lifelong maintenance after initial improvement.

\section{Patient-focused perspectives: quality of life and patient satisfaction}

As stated earlier, there is a significant burden on the quality of life (QoL) in patients with rosacea, not only cosmetically due to their unwanted appearance but also due to the painful and irritating symptoms associated with the condition. Rosacea patients present with higher rates of anxiety and depression, develop greater general symptom intensity, experience difficulty functioning in everyday life, perceive general health more negatively, and subjectively feel they receive poor social support. ${ }^{144}$ They experience not only high loads of stress, but also embarrassment and social phobia as a result of their skin condition. Contrary to historical belief, rosacea patients have the highest comorbidity of depression, while alcohol abuse has a very mild association. ${ }^{145}$

Clinical trials have tried to measure outcomes by improvement in patient QoL, which may be assessed by various standardized questionnaires, such as the Dermatology Life Quality Index (DLQI), Skindex-29, and rosacea-specific QoL indices. The DLQI questionnaire is a reliable and valid instrument that is quite sensitive to QoL changes brought about by various treatment options. ${ }^{146,147}$ The rosacea-specific QoL and Skindex-29 measure which characteristics of rosacea affect the patient's life the most. Interestingly, flushing was found to be the most troubling symptom reported by patients affected by rosacea, stressing the importance of treating both the cosmetic and medical aspects of this condition. ${ }^{148}$

The DLQI questionnaire evaluates QoL with ten questions covering the feelings, daily activities, clothing, physical or social activities, exercise, education or job, relationships, and treatments impacted by dermatological conditions. Developed in 1994, this measure has been utilized in the study of a variety of diseases, including rosacea. Variables are scored by patients on a Likert scale and final results range from 0 to 30, with higher numbers signifying more extreme effects on a patient's QoL. Tan and Tope first applied this outcome measure to 16 ETR patients treated with PDL, and demonstrated a significant reduction from 7.8 to 1.9 at 2 months following two laser treatment sessions. ${ }^{91}$ When measured in 20 patients before and after $595 \mathrm{~nm}$ PDL treatment, averaged DLQI scores decreased from 17.3 to 4.3 , indicating a significant improvement in QoL from the patient perspective. ${ }^{149}$ Finally, Menezes et al used this index to assess the impact of PDL in a prospective study of 22 patients with ETR and found a significant reduction from 5.6 before treatment to 1.5 after three treatment sessions. ${ }^{150}$

\section{Recommendations}

\section{Systemic isotretinoin therapy}

As previously discussed, isotretinoin is a viable alternative for recalcitrant cases of rosacea. In a large-scale, placebo-controlled, randomized, 12-week, multicenter study, 
Gollnick et al demonstrated complete remission in 24\% and marked improvement in $57 \%$ of patients with isotretinoin $0.3 \mathrm{mg} / \mathrm{kg}$ therapy daily, in contrast with remission in $14 \%$ and marked improvement in $55 \%$ of patients treated with doxycycline $100 \mathrm{mg}$ daily for 14 days, then $50 \mathrm{mg}$ daily. Patients treated with isotretinoin rated treatment results at the end of the study as "excellent improvement" more frequently, at $32.6 \%$ in comparison with $24.2 \%$ for patients treated with doxycycline. ${ }^{67}$

\section{OnabotulinumtoxinA injections}

Anecdotal results of reduced erythema and acne with the use of OnabotulinumtoxinA (Botox ${ }^{\circledR}$, Allergan, Irvine, CA, USA) for cosmetic purposes led Dayan et al to experiment further in 13 patients with rosacea. ${ }^{151}$ Over the course of 2 years, patients received intralesional microdroplet injections $(0.05 \mathrm{~mL})$ of onabotulinumtoxinA in a dilution of $7 \mathrm{~mL}$ of saline solution per 100 units. The results indicated significant reduction in erythema and flushing of the affected area 2-4 weeks after treatment. Their predecessors reported similar results after a 26-year-old male was injected with 10 units of onabotulinumtoxin $\mathrm{A}$ at $1 \mathrm{~cm}$ intervals into one cheek. ${ }^{152}$

\section{Excel $\vee$ laser: combining KTP and Nd:YAG}

The new Excel V laser combines KTP and Nd:YAG, two previously discussed lasers with different wavelengths. KTP emits light at a wavelength of $532 \mathrm{~nm}$, which targets redness, hyperpigmentation, and damaged capillaries at the surface of the skin, while Nd:YAG has a laser wavelength of 1,064 nm designed for treating more deep blood vessels with larger diameters. Following absorption of energy, abnormal blood vessels are thermosealed while hyperpigmented lesions are fragmented, resulting in an overall improved appearance.

\section{Conclusion}

Rosacea is a chronic inflammatory condition without a permanent cure. Recent advances in combination treatments offer treatments with better initial results and longer-term maintenance than in the past. The fundamental key for successful management of rosacea is based on identification of the specific subtype, understanding the severity of presentation, and tailoring treatments to best suit the expectations of the patient. Continued research into both the cosmetic and medical aspects of this condition will further define treatment protocols that ultimately will refine the current options available to patients.

\section{Acknowledgments}

The patient consent was received for the use of their images.

\section{Disclosure}

The authors report no conflicts of interest in this work.

\section{References}

1. Cribier B. Medical history of the representation of rosacea in the 19th century. J Am Acad Dermatol. 2013;69(6 Suppl 1):S2-S14.

2. Crawford GH, Pelle MT, James WD. Rosacea: I. Etiology pathogenesis, and subtype classification. J Am Acad Dermatol. 2004;51(3):327-341.

3. Wilkin J, Dahl M, Detmar M, et al. Standard classification of rosacea: Report of the National Rosacea Society Expert Committee on the classification and staging of rosacea. J Am Acad Dermatol. 2002;46(4):584-587.

4. Abram K, Silm H, Oona M. Prevalence of rosacea in an Estonian working population using a standard classification. Acta Derm Venereol. 2010;90(3):269-273.

5. Tan J, Berg M. Rosacea: current state of epidemiology. J Am Acad Dermatol. 2013;69(6 Suppl 1):S27-S35.

6. Lomholt G. Prevalence of skin diseases in a population; a census study from the Faroe Islands. Dan Med Bull. 1964;11:1-7.

7. Romanowicz M, Stephenson JJ, Del Rosso JQ, Lenhart G. Healthcare utilization and costs of patients with rosacea in an insured population. J Drugs Dermatol. 2008;7(1):41-49.

8. McAleer MA, Fitzpatrick P, Powell FC. Papulopustular rosacea: prevalence and relationship to photodamage. J Am Acad Dermatol. 2010;63(1):33-39.

9. Schaefer I, Rustenbach SJ, Zimmer L, Augustin M. Prevalence of skin diseases in a cohort of 48,665 employees in Germany. Dermatology. 2008;217(2):169-172.

10. Augustin M, Herberger K, Hintzen S, Heigel H, Franzke N, Schafer I. Prevalence of skin lesions and need for treatment in a cohort of 90,880 workers. Br J Dermatol. 2011;165(4):865-873.

11. Berg M, Liden S. An epidemiological study of rosacea. Acta Derm Venereol. 1989;69(5):419-423.

12. Guttman C. Rosacea prevalence underestimated. Dermatology Times. 2006;27:48-57.

13. Tüzün Y, Wolf R, Kutlubay Z, Karakuş O, Engin B. Rosacea and rhinophyma. Clin Dermatol. 2014;32(1):35-46.

14. Vieira AC, Mannis MJ. Ocular rosacea: common and commonly missed. J Am Acad Dermatol. 2013;69(6 Suppl 1):S36-S41.

15. Steinhoff M, Buddenkotte J, Aubert J, et al. Clinical, cellular and molecular aspects in the pathophysiology of rosacea. J Investig Dermatol Symp Proc. 2011;15(1):2-11.

16. Steinhoff M, Schauber J, Leyden J. New insights into rosacea pathophysiology: a review of recent findings. $J$ Am Acad Dermatol. 2013;69(6 Suppl 1):S15-S26.

17. Schauber J, Gallo RL. The vitamin D pathway: a new target for control of the skin's immune response? Exp Dermatol. 2008;17(8):633-639.

18. Meyer-Hoffert U, Schroder JM. Epidermal proteases in the pathogenesis of rosacea. J Investig Dermatol Symp Proc. 2011;15(1):16-23.

19. Georgala S, Katoulis AC, Kylafis GD, Koumantaki-Mathioudaki E, Georgala C, Aroni J. Increased density of Demodex folliculorum and evidence of delayed hypersensistivity reaction in subjects with papulopustular rosacea. J Eur Acad Dermatol Venereol. 2001;15(5): 441-444.

20. Holmes AD. Potential role of microorganisms in the pathogenesis of rosacea. J Am Acad Dermatol. 2013;69(6):1025-1032.

21. Aubdool AA, Brain SD. Neurovascular aspects of skin neurogenic inflammation. J Investig Dermatol Symp Proc. 2011;15(1):33-39.

22. Moore A, Kempers S, Mirakawa G, et al. Long-term safety and efficacy of once-daily topical brimonidine tartrate gel $0.5 \%$ for the treatment of moderate to severe facial erythema of rosacea: results of a 1-year open-label study. J Drugs Dermatol. 2014;13(1):56-61. 
23. Fowler J, Jarratt M, Moore A, et al. Once-daily topical brimonidine tartrate gel $0.5 \%$ is a novel treatment for moderate to severe facial erythema of rosacea: results of two multicenter, randomized and vehiclecontrolled studies. Br J Dermatol. 2012;166(3):633-641.

24. Jackson JM, Fowler J, Moore A, et al. Improvement in facial erythema within 30 minutes of initial application of brimonidine tartrate in patients with rosacea. J Drugs Dermatol. 2014;13(6):699-704.

25. Shanler SD, Ondo AL. Successful treatment of the erythema and flushing of rosacea using a topically applied selective alpha 1-adrenergic receptor agonist, oxymetazoline. Arch Dermatol. 2007;143(11):1369-1371.

26. Thomas K, Yelverton CB, Yentzer BA, Balkrishnan R, Fleischer AB Jr, Feldman SR. The cost-effectiveness of rosacea treatments. J Dermatol Treat. 2009;20(2):72-75.

27. Elewski BE, Fleischer AB Jr, Pariser DM. A comparison of $15 \%$ azelaic acid gel and $0.75 \%$ metronidazole gel in the topical treatment for papulopustular rosacea: results of a randomized trial. Arch Dermatol. 2003;139(11):1444-1450.

28. Wolf JE Jr, Kerrouche N, Arsonnaud S. Efficacy and safety of once-daily metronidazole $1 \%$ gel compared with twice-daily azelaic acid $15 \%$ gel in the treatment of rosacea. Cutis. 2006;77(4 Suppl):3-11.

29. Trumbore MW, Goldstein JA, Gurge RM. Treatment of papulopustular rosacea with sodium sulfacetamide $10 \%$ - sulfur 5\% emollient foam. J Drugs Dermatol. 2009;8(3):299-304.

30. Del Rosso JQ, Thiboutot D, Gallo R, et al. Consensus recommendations from the American Acne and Rosacea Society on the management of rosacea. Part 2: a status report on topical agents. Cutis. 2013;92(6): 277-284.

31. Karabulut AA, Izol Serel B, Eksioglu HM. A randomized, single-blind, placebo-controlled, split-face study with pimecrolimus cream $1 \%$ for papulopustular rosacea. J Eur Acad Dermatol Venereol. 2008;22(6): 729-734.

32. Crawford KM, Russ B, Bostrom P. Pimecrolimus for treatment of acne rosacea. Skinmed. 2005;4(3):147-150.

33. Koca R, Altinyazar HC, Ankarali H, Muhtar S, Tekin NS, Cinar S. A comparison of metronidazole $1 \%$ cream and pimecrolimus $1 \%$ cream in the treatment of patients with papulopustular rosacea: a randomized open-label clinical trial. Clin Exp Dermatol. 2010;35(3):251-256.

34. Kocak M, Yağli S, Vahapoğlu G, Eksioğlu M. Permethrin 5\% cream versus metronidazole $0.75 \%$ gel for the treatment of papulopustular rosacea: A randomized double-blind placebo-controlled study. Dermatology. 2002;205(3):265-270.

35. Signore RJ. A pilot study of 5 percent permethrin cream versus 0.75 percent metronidazole gel in acne rosacea. Cutis. 1995;56(3)177-179.

36. Allen KJ, Davis CL, Billings SD, Mousdicas N. Recalcitrant papulopustular rosacea in an immunocompetent patient responding to combination therapy with oral ivermectin and topical permethrin. Cutis. 2007;80(2):149-151.

37. Stein L, Kircik L, Fowler J, et al. Efficacy and safety of ivermectin 1\% cream in treatment of papulopustular rosacea: results of two randomized, double-blind, vehicle-controlled pivotal studies. J Drugs Dermatol. 2014;13(3):316-323.

38. Forstinger C, Kittler H, Binder M. Treatment of rosacea-like demodicidosis with oral ivermectin and topical permethrin cream. J Am Acad Dermatol. 1999;41(5 Pt 1)775-777.

39. Pariser DM, Meinking TL, Bell M, Ryan WG. Topical $0.5 \%$ ivermectin lotion for treatment of head lice. $N$ Engl J Med. 2012;367(18): 1687-1693.

40. Filho PA, Hazarbassanov RM, Grisolia AB, Pazos HB, Kaiserman I, Gomes JA. The efficacy of oral ivermectin for the treatment of chronic blepharitis in patients tested positive for Demodex spp. Br JOphthalmol. 2011;95(6):893-895.

41. Breneman D, Savin R, VandePol C, Vamvakias G, Levy S, Leyden J. Double-blind, randomized, vehicle-controlled clinical trial of once-daily benzoyl peroxide/clindamycin topical gel in the treatment of patients with moderate to severe rosacea. Int J Dermatol. 2004;43(5):381-387.

42. Leyden JJ. Randomized, phase 2, dose-ranging study in the treatment of rosacea with encapsulated benzoyl peroxide gel. J Drugs Dermatol. 2014;13(6):685-688.
43. Emer J, Waldorf H, Berson D. Botanicals and anti-inflammatories: natural ingredients for rosacea. Semin Cutan Med Surg. 2011;30(3): 148-155.

44. Baldwin H, Berson D, Vitale M, Yatskayer M, Chen N, Oresajo C. Clinical effects of a novel topical composition on persistent redness observed in patients who had been successfully treated with topical or oral therapy for papulopustular rosacea. J Drugs Dermatol. 2014;13(3):326-331.

45. Ferrari A, Diehl C. Evaluation of the efficacy and tolerance of a topical gel with $4 \%$ quassia extract in the treatment of rosacea. J Clin Pharmacol. 2012;52(1):84-88.

46. Schlesinger TE, Powell CR. Efficacy and tolerability of low molecular weight hyaluronic acid sodium salt $0.2 \%$ cream in rosacea. J Drugs Dermatol. 2013;12(6):664-667.

47. Gariboldi S, Palazzo M, Zanobbio L, et al. Low molecular weight hyaluronic acid increases the self-defense of skin epithelium by induction of beta-defensin 2 via TLR2 and TLR4. J Immunol. 2008;181(3): 2103-2110.

48. Del Rosso JQ, Webster GF, Jackson M, et al. Two randomized phase III clinical trials evaluating anti-inflammatory dose doxycycline (40-mg doxycycline, USP capsules) administered once daily for treatment of rosacea. J Am Acad Dermatol. 2007;56(5):791-802.

49. Kanada KN, Nakatsuji T, Gallo RL. Doxycycline indirectly inhibits proteolytic activation of tryptic kallikrein-related peptidases and activation of cathelicidin. J Invest Dermatol. 2012;132(5):1435-1442.

50. Layton A, Thiboutot D. Emerging therapies in rosacea. J Am Acad Dermatol. 2013;69(6 Suppl 1):S57-S65.

51. Del Rosso JQ, Thiboutot D, Gallo R, et al. Consensus recommendations from the American Acne and Rosacea Society on the management of rosacea. Part 3: a status report on systemic therapies. Cutis. 2014;93(1): 18-28.

52. Del Rosso JQ, Schlessinger J, Werschler P. Comparison of antiinflammatory dose doxycycline versus doxycycline $100 \mathrm{mg}$ in the treatment of rosacea. J Drugs Dermatol. 2008;7(6):573-576.

53. Del Rosso JQ. The ORCA (Oracea for Rosacea: a Community-based Assessment) trial: a large-scale, phasae 4 trial in papulopustular rosacea. Cutis. 2010;86(5 Suppl):4-6.

54. Webster GF. An open-label, community-based, 12-week assessment of the effectiveness and safety of monotherapy with doxycycline $40 \mathrm{mg}$ (30-mg immediate-release and 10-mg delayed-release beads). Cutis. 2010;86(5 Suppl):7-15.

55. Alexis AF, Webster G, Preston NJ, Caveney SW, Gottschalk RW. Effectiveness and safety of once-daily doxycycline capsules as monotherapy in patients with rosacea: an analysis by Fitzpatrick skin type. J Drugs Dermatol. 2012;11(10):1219-1222.

56. Jackson JM, Kircik LH, Lorenz DJ. Efficacy of extended-release $45 \mathrm{mg}$ oral minocycline and extended-release $45 \mathrm{mg}$ oral minocycline plus $15 \%$ azelaic acid in the treatment of acne rosacea. J Drugs Dermatol. 2013;12(3):292-298.

57. Sobolewska B, Doycheva D, Deuter C, Pfeffer I, Schaller M, Zierhut M. Treatment of ocular rosacea with once-daily low-dose doxycycline. Cornea. 2014;33(3):257-260.

58. Pfeffer I, Borelli C, Zierhut M, Schaller M. Treatment of ocular rosacea with $40 \mathrm{mg}$ doxycycline in a slow release form. J Dtsch Dermatol Ges. 2011;9(11):904-907.

59. Mantelli F, Di Zazzo A, Sacchetti M, Dianzani C, Lambiase A, Bonini S. Topical azithromycin as a novel treatment for ocular rosacea. Ocul Immunol Inflamm. 2013;21(5):371-377.

60. Thiboutot DM, Fleischer AB, Del Rosso JQ, Rich P. A multicenter study of topical azelaic acid 15\% gel in combination with oral doxycycline as initial therapy and azelaic acid 15\% gel as maintenance monotherapy. J Drugs Dermatol. 2009;8(7):639-648.

61. Fowler JF Jr. Combination effect of anti-inflammatory dose doxycycline (40-mg doxycycline, USP monohydrate controlled-release capsules) and metronidazole topical gel $1 \%$ in the treatment of rosacea. J Drugs Dermatol. 2007;6(6):641-645.

62. Modi S, Harting M, Rosen T. Azithromycin as an alternative rosacea therapy when tetracyclines prove problematic. J Drugs Dermatol. 2008;7(9):898-899. 
63. Kim JH, OhYS, Choi EH. Oral azithromycin for treatment of intractable rosacea. J Korean Med Sci. 2011;26(5):694-696.

64. Sehgal VN, Sharma S, Sardana K. Rosacea/acne rosacea: efficacy of combination therapy of azithromycin and topical $0.1 \%$ tacrolimus ointment. J Eur Acad Dermatol Venereol. 2008;22(11):1366-1368.

65. Pye RJ, Burton JL. Treatment of rosacea by metronidazole. Lancet. 1976;1(7971):1211-1212.

66. Park H, Del Rosso JQ. Use of oral isotretinoin in the management of rosacea. J Clin Aesthet Dermatol. 2011;4(9):54-61.

67. Gollnick H, Blume-Peytavi U, Szabo EL, et al. Systemic isotretinoin in the treatment of rosacea - doxycycline- and placebo-controlled, randomized clinical study. J Dtsch Dermatol Ges. 2010;8(7):505-515.

68. Hofer T. Continuous 'microdose' isotretinoin in adult recalcitrant rosacea. Clin Exp Dermatol. 2004;29(2):204-205.

69. Palmer RA, Sidhu S, Goodwin PG. 'Microdose' isotretinoin. $\mathrm{Br} J$ Dermatol. 2000;143(1):205-206.

70. Pavlis MB, Lieblich L. Isotretinoin-induced skin fragility in a teenaged athlete: a case report. Cutis. 2013;92(1):33-34.

71. Holmes SC, Thomson J. Isotretinoin and skin fragility. Br J Dermatol. 1995;132(1):165.

72. Rubenstein R, Roenigk HH Jr, Stegman SJ, Hanke CW. Atypical keloids after dermabrasion of patients taking isotretinoin. J Am Acad Dermatol. 1986;15(2 Pt 1):280-285.

73. Zachariae H. Delayed wound healing and keloid formation following argon laser treatment or dermabrasion during isotretinoin treatment. Br J Dermatol. 1988;118(5):703-706.

74. Chandrashekar BS, Varsha DV, Vasanth V, Madura C, Rajashekar ML. Safety of performing invasive acne scar treatment and laser hair removal in patients on oral isotretinoin: a retrospective study of 110 patients. Int J Dermatol. 2014;53(10):1281-1285.

75. Yoon JH, Park EJ, Kwon IH, et al. Concomitant use of an infrared fractional laser with low-dose isotretinoin for the treatment of acne and acne scars. J Dermatolog Treat. 2014;25(2):142-146.

76. Sharquie KE, Najim RA, Al-Salman HN. Oral zinc sulfate in the treatment of rosacea: a double-blind, placebo controlled study. Int $J$ Dermatol. 2006;45(7):857-861.

77. Bamford JT, Gessert CE, Haller IV, Kruger K, Johnson BP. Randomized, double-blind trial of $220 \mathrm{mg}$ zinc sulfate twice daily in the treatment of rosacea. Int J Dermatol. 2012;51(4):459-462.

78. Anderson RR, Parish JA. Selective photothermolysis: precise microsurgery by selective absorption of pulsed radiation. Science. 1983; 220(4596):524-527.

79. Bencini PL, Tourlaki A, De Giorgi V, Galimberti M. Laser use for cutaneous vascular alterations of cosmetic interest. Dermatol Ther. 2012;25(4):340-351.

80. Cameron H, Ibbotson SH, Ferguson J, Dawe RS, Moseley H. A randomized, blinded, controlled study of the clinical relevance of matching pulse duration to thermal relaxation time when treating facial telangiectasia. Lasers Med Sci. 2005;20(3-4):117-121.

81. Tanghetti E, Del Rosso JQ, Thiboutot D, et al. Consensus recommendations from the American acne and rosacea society on the management of rosacea. Part 4: a status report on physical modalities and devices. Cutis. 2014;93(2):71-76.

82. Mansouri Y, Goldenberg G. Devices and topical agents for rosacea management. Cutis. 2014;94(1):21-25.

83. Arndt KA. Argon laser therapy of small cutaneous vascular lesions. Arch Dermatol. 1982;118(4):220-224.

84. Laube S, Lanigan SW. Laser treatment of rosacea. J Cosmet Dermatol. 2002;1(4):188-195.

85. Erceg A, de Jong EM, van de Kerkhof PC, Seyger MM. The efficacy of pulsed dye laser treatment for inflammatory skin diseases: a systematic review. J Am Acad Dermatol. 2013;69(4):609-615.

86. Butterwick KJ, Butterwick LS, Han A. Laser and light therapies for acne rosacea. J Drugs Dermatol. 2006;5(1)35-39.

87. Bernstein EF, Kligman A. Rosacea treatment using the new-generation, high-energy, $595 \mathrm{~nm}$, long pulse-duration pulsed-dye laser. Lasers Surg Med. 2008;40(4):233-239.
88. Lowe NJ, Behr KL, Fitzpatrick R, Goldman M, Ruiz-Esparza J. Flash lamp pumped dye laser for rosacea-associated telangiectasia and erythema. J Dermatol Surg Oncol. 1991;17(6):522-525.

89. Alam M, Dover JS, Arndt KA. Treatment of facial telangiectasia with variable-pulse high-fluence pulsed-dye laser: comparison of efficacy with fluences immediately above and below the purpura threshold. Dermatol Surg. 2003;29(7):681-685.

90. Jasim ZF, Woo WK, Handley JM. Long-pulsed (6-ms) pulsed dye laser treatment of rosacea-associated telangiectasia using subpurpuric clinical threshold. Dermatol Surg. 2004;30(1):37-40.

91. Tan SR, Tope WD. Pulsed dye laser treatment of rosacea improves erythema, symptomatology, and quality of life. J Am Acad Dermatol. 2004:51(4):592-599.

92. Tan ST, Bialostocki A, Armstrong JR. Pulsed dye laser therapy for rosacea. Br J Plast Surg. 2004;57(4):303-310.

93. Lonne-Rahm S, Nordlind K, Edstrom DW, Ros AM, Berg M. Laser treatment of rosacea: a pathoetiological study. Arch Dermatol. 2004; 140(11):1345-1349.

94. Togsverd-Bo K, Wiegell SR, Wulf HC, Haedersdal M. Short and limited effect of long-pulse dye laser alone and in combination with photodynamic therapy for inflammatory rosacea. J Eur Acad Dermatol Venereol. 2009;23(2):200-201.

95. Kim TG, Roh HJ, Cho SB, Lee JH, Lee SJ, Oh SH. Enhancing effect of pretreatment with topical niacin in the treatment of rosacea-associated erythema by $585-\mathrm{nm}$ pulsed dye laser in Koreans: a randomized, prospective, split-face trial. Br J Dermatol. 2011;164(3):573-579.

96. Kashlan L, Graber EM, Arndt KA. Hair dryer use to optimize pulsed dye laser treatment in rosacea patients. $J$ Clin Aesthet Dermatol. 2012;5(6):41-44.

97. Lanigan S. Reduction of pain in the treatment of vascular lesions with a pulsed dye laser and pneumatic skin flattening. Lasers Med Sci. 2009;24(4):617-620.

98. Piccolo D, Di Marcantonio D, Crisman G, et al. Unconventional use of intense pulsed light. Biomed Res Int. 2014;2014:618206.

99. Angermeier MC. Treatment of facial vascular lesions with intense pulsed light. J Cutan Laser Ther. 1999;1(2):95-100.

100. Taub AF. Treatment of rosacea with intense pulsed light. $J$ Drugs Dermatol. 2003;2(3):254-259.

101. Mark KA, Sparacio RM, Voigt A, Marenus K, Sarnoff DS. Objective and quantitative improvement of rosacea-associated erythema after intense pulsed light treatment. Dermatol Surg. 2003;29(6):600-604.

102. Schroeter CA, Haff-von Below S, Neumann HA. Effective treatment of rosacea using intense pulsed light systems. Dermatol Surg. 2005; 31(10): 1285-1289.

103. Papageorgiou P, Clayton W, Norwood S, Chopra S, Rustin M. Treatment of rosacea with intense pulsed light: significant improvement and long-lasting results. Br J Dermatol. 2008;159(3):628-632.

104. Kassir R, Kolluru A, Kassir M. Intense pulsed light for the treatment of rosacea and telangiectasias. J Cosmet Laser Ther. 2011;13(5): 216-222.

105. Sperber BR, Walling HW, Arpey CF, Whitaker DC. Vesiculobullous eruption from intense pulsed light treatment. Dermatol Surg. 2005; 31(3):345-348.

106. Taub AF, Devita EF. Successful treatment of erythematotelangiectatic rosacea with pulsed light and radiofrequency. J Clin Aesthet Dermatol. 2008;1(1):37-40.

107. Neuhaus IM, Zane LT, Tope WD. Comparative efficacy of nonpurpuragenic pulsed dye laser and intense pulsed light for erythematotelangiectatic rosacea. Dermatol Surg. 2009;35(6):920-928.

108. Lane JE, Khachemoune A. Use of intense pulsed light to treat refractory granulomatous rosacea. Dermatol Surg. 2010;36(4):571-573.

109. Liu J, Liu J, Ren Y, Li B, Lu S. Comparative efficacy of intense pulsed light for different erythema associated with rosacea. $J$ Cosmet Laser Ther. 2014;16(6):324-327.

110. Lim HS, Lee SC, Won YH, Lee JB. The efficacy of intense pulsed light for treating erythematotelangiectatic rosacea is related to severity and age. Ann Dermatol. 2014;26(4):491-495. 
111. Tsunoda K, Takahashi K, Ogino N, Yoshida A, Akasaka T. Treatment of facial telangiectasia with a small spot of intense pulsed light: a case series of three patients. J Dermatol. 2014;41(7):638-641.

112. Pelle MT, Crawford GH, James WD. Rosacea: II. Therapy. J Am Acad Dermatol. 2004;51(4):499-512.

113. Bassichis BA, Swamy R, Dayan SH. Use of the KTP laser in the treatment of rosacea and solar lentigines. Facial Plast Surg. 2004;20(1): 77-83.

114. Becher GL, Cameron H, Moseley H. Treatment of superficial vascular lesions with the KTP 532-nm laser: experience with 647 patients. Lasers Med Sci. 2014;29(1):267-271.

115. Clark C, Cameron H, Moseley H, Ferguson J, Ibbotson SH. Treatment of superficial cutaneous vascular lesions: experience with the KTP $532 \mathrm{~nm}$ laser. Lasers Med Sci. 2004;19(1):1-5.

116. Miller A. Treatment of erythematotelangiectatic rosacea with a KTP YAG laser. J Drugs Dermatol. 2005;4(6):760-762.

117. West TB, Alster TS. Comparison of the long-pulse dye (590-595 nm) and KTP $(532 \mathrm{~nm})$ lasers in the treatment of facial and leg telangiectasias. Dermatol Surg. 1998;24(2):221-226.

118. George J, Bensafi A, Schmitt AM, et al. Validation of a non-contact technique for local skin temperature measurements. Skin Res Technol. 2008;14(4):381-384.

119. Salem SA, Abdel Fattah NS, Tantawy SM, El-Badawy NM, Abd ElAziz YA. Neodymium-yttrium aluminum garnet laser versus pulsed dye laser in erythemato-telangiectatic rosacea: comparison of clinical efficacy and effect on cutaneous substance (P) expression. $J$ Cosmet Dermatol. 2013;12(3):187-194.

120. Alam M, Voravutinon N, Warycha M, et al. Comparative effectiveness of nonpurpuragenic 595-nm pulsed dye laser and microsecond 1064-nm neodymium:yttrium-aluminum-garnet laser for treatment of diffuse facial erythema: a double-blind randomized controlled trial. J Am Acad Dermatol. 2013;69(3):438-443.

121. Matton G, Pickrell K, Huger W, Pound E. The surgical treatment of rhinophyma: an analysis of 57 cases. Plast Reconstr Surg. 1962;30: 403-414.

122. Lim RY. Contact Nd:YAG laser excision of rhinophyma. $W V$ Med $J$. 1994;90(2):62-63.

123. Wenig BL, Weingarten RT. Excision of rhinophyma with Nd:YAG laser: a new technique. Laryngoscope. 1993;103(1 Pt 1):101-103.

124. Apfelberg DB. Side effects, sequelae, and complications of carbon dioxide laser resurfacing. Aesthet Surg J. 1997;17(6):365-372.

125. Campolmi P, Bonan P, Cannarozzo G, et al. Highlights of thirty-year experience of $\mathrm{CO}_{2}$ laser use at the Florence (Italy) department of dermatology. ScientificWorldJournal. 2012;2012:546528.

126. Shapshay SM, Strong MS, Anastasi GW, Vaughan CW. Removal of rhinophyma with the carbon dioxide laser: a preliminary report. Arch Otolaryngol. 1980;106(5):257-259.

127. Maden V, Ferguson JE, August PJ. Carbon dioxide laser treatment of rhinophyma: a review of 124 patients. Br J Dermatol. 2009;161(4): 814-818.

128. Lim SW, Lim SW, Bekhor P. Rhinophyma: carbon dioxide laser with computerized scanner is still an outstanding treatment. Australas $J$ Dermatol. 2009;50(4):289-293.

129. Cravo M, Canelas MM, Cardoso JC, Vieira R, Figueiredo A. Combined carbon dioxide laser and bipolar electrocoagulation: another option to treat rhinophyma. J Dermatol Treat. 2009;20(3):146-148.

130. Rai S, Madan V. Treatment of metophyma with the carbon dioxide laser. Dermatol Surg. 2012;38(3):513-515.

131. Moreira A, Leite I, Guedes R, Baptista A, Mota G. Surgical treatment of rhinophyma using carbon dioxide $\left(\mathrm{CO}_{2}\right)$ laser and pulsed dye laser (PDL). J Cosmet Laser Ther. 2010;12(2):73-76.

132. Serowka KL, Saedi N, Dover JS, Zachary CB. Fractionated ablative carbon dioxide laser for the treatment of rhinophyma. Lasers Surg Med. 2014;46(1):8-12.
133. Singh S, Peterson JD, Friedman PM. Management of mild to moderate rhinophyma using ablative fractional photothermolysis. Dermatol Surg. 2013;39(7):1110-1113.

134. Carradino B, Di Lorenzo S, Moschella F. "Downward steps techinique" with $\mathrm{CO}_{2}$ ultrapulsed laser for the treatment of rhinophyma: our protocol. Acta Chir Plast. 2013;55(1):16-18.

135. Bassi A, Campolmi P, Dindelli M, et al. Laser surgery in rhinophyma. $G$ Ital Dermatol Venereol. September 18, 2014. [Epub ahead of print.]

136. Lazzeri D, Larcher L, Huemer GM, et al. Surgical correction of rhinophyma: comparison of two methods in a 15-year-long experience. J Craniomaxillofac Surg. 2013;41(5):429-436.

137. Orenstein A, Haik J, Tamir J, et al. Treatment of rhinophyma with Er:YAG laser. Lasers Surg Med. 2001;29(3):230-235.

138. Goon PK, Dalal M, Peart FC. The gold standard for decortication of rhinophyma: combined erbium-YAG/CO $\mathrm{CO}_{2}$ laser. Aesthetic Plast Surg. 2004;28(6):456-460.

139. Fincher EF, Gladstone HB. Use of a dual-mode erbium:YAG laser for the surgical correction of rhinophyma. Arch Facial Plast Surg. 2004;6(4):267-271.

140. Noh S, Sin JU, Jung JY, Lee JH. A case of sebaceous hyperplasia maintained on low-dose isotretinoin after carbon dioxide laser treatment. In J Dermatol. 2014;53(2):e151-e153.

141. McDonald SK, Goh MS, Chong AH. Successful treatment of cyclosporine-induced sebaceous hyperplasia with oral isotretinoin in two renal transplant recipients. Australas J Dermatol. 2011;52(3): 227-230.

142. Yu C, Shahsavari M, Stevens G, Liskanich R, Horowitz D. Isotretinoin as monotherapy for sebaceous hyperplasia. J Drugs Dermatol. 2010; 9(6):699-701.

143. Del Rosso JQ. Advances in understanding and managing rosacea. Part 2: the central role, evaluation, and medical management of diffuse and persistent facial erythema of rosacea. $J$ Clin Aesthet Dermatol. 2012;5(3):26-36.

144. Moustafa F, Lewallen RS, Feldman SR. The psychosocial impact of rosacea and the influence of current management options. $\mathrm{J} \mathrm{Am} \mathrm{Acad}$ Dermatol. 2014;71(5):973-980.

145. Gupta MA, Gupta AK, Chen SJ, Johnson AM. Comorbidity of rosacea and depression; an analysis of the National Ambulatory Medical Care Survey and National Hospital Ambulatory Care SurveyOutpatient department data collected by the US National Center for Health Statistics from 1995 to 2002. Br J Dermatol. 2005;153(6): 1176-1181.

146. Aksoy B, Altaykan-Hapa A, Egemen D, Karagöz F, Atakan N. The impact of rosacea on quality of life: effects of demographic and clinical characteristics and various treatment modalities. Br J Dermatol. 2010;163(4):719-725.

147. Finlay AY, Khan GK. Dermatology life quality index (DLQI) a simple practical measure for routine clinical use. Clin Exp Dermatol. 1994;19(3):210-216.

148. Nicholson K, Abramova L, Chren MM, Yeung J, Chon SY, Chen SC. A pilot quality-of-life instrument for acne rosacea. $J$ Am Acad Dermatol. 2007;57(2):213-221.

149. Shim TN, Abdullah $\mathrm{H}$. The effect of pulsed dye laser on the dermatology life quality index in erythematotelangiectatic rosacea patients: an assessment. J Clin Aesthet Dermatol. 2013;6(4):30-32.

150. Menezes N, Moreira A, Mota G, Baptista A. Quality of life and rosacea: pulsed dye laser impact. J Cosmet Laser Ther. 2009;11(3):139-141.

151. Dayan SH, Pritzker RN, Arkins JP. A new treatment regimen for rosacea: onabotulinumtoxinA. J Drugs Dermatol. 2012;11(12): e76-e79.

152. Yuraitis M, Jacob CI. Botulinum toxin for the treatment of facial flushing. Dermatol Surg. 2004;30(1):102-104. 


\section{Publish your work in this journal}

Clinical, Cosmetic and Investigational Dermatology is an international, peer-reviewed, open access, online journal that focuses on the latest clinical and experimental research in all aspects of skin disease and cosmetic interventions. All areas of dermatology will be covered; contributions will be welcomed from all clinicians and basic science researchers globally. This journal is indexed on CAS. The manuscript management system is completely online and includes a very quick and fair peer-review system, which is all easy to use. Visit http://www.dovepress.com/testimonials.php to read real quotes from published authors. 